\title{
Lexis
}

Journal in English Lexicology

$11 \mid 2018$

Lexis in Languages for Specific Purposes (LSP)

\section{Médiation linguistique et activités de traduction dans l'enseignement des langues de spécialité : une pratique didactique revisitée}

Eleftheria Dogoriti, Georges Iseris et Theodore Vyzas

\section{(2) OpenEdition \\ Journals}

Édition électronique

URL : http://journals.openedition.org/lexis/1210

DOI : $10.4000 /$ lexis. 1210

ISSN : 1951-6215

Éditeur

Université Jean Moulin - Lyon 3

Référence électronique

Eleftheria Dogoriti, Georges Iseris et Theodore Vyzas, « Médiation linguistique et activités de traduction dans l'enseignement des langues de spécialité : une pratique didactique revisitée », Lexis [En ligne], 11 | 2018, mis en ligne le 30 avril 2018, consulté le 19 avril 2019. URL : http:// journals.openedition.org/lexis/1210 ; DOI : 10.4000/lexis.1210

Ce document a été généré automatiquement le 19 avril 2019.

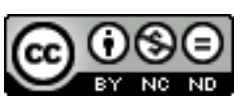

Lexis is licensed under a Creative Commons Attribution-NonCommercial-NoDerivatives 4.0 International License. 


\title{
Médiation linguistique et activités de traduction dans l'enseignement des langues de spécialité : une pratique didactique revisitée
}

\author{
Eleftheria Dogoriti, Georges Iseris et Theodore Vyzas
}

\section{Introduction}

1 Le cursus LEA à visée entrepreneuriale qui est offert dans notre Département de gestion situé à Igouménitsa, en Grèce, permet aux diplômés de trouver du travail dans des entreprises ou des organisations internationales. Il met fortement l'accent sur des compétences communicatives dans deux langues de spécialité ainsi que sur la compétence en traduction spécialisée. Nous pensons que les propositions du Cadre Européen Commun de Référence pour les Langues (CECR) publié par le Conseil de l'Europe - première version en 2001 et version amplifiée en 2016 - en matière de médiation linguistique sont d'une grande utilité pour revisiter la conception des cours de langue et de traduction dans notre Département: le CECR réintroduit la traduction en cours de Langue Étrangère (dorénavant LE), par le biais du concept de médiation linguistique qui comprend les activités de traduction et d'interprétation, aussi bien à l'écrit qu'à l'oral.

2 L'objectif de cet article est de présenter une démarche exploratoire prenant appui sur les descripteurs du CECR récemment développés pour la médiation linguistique, qui vise la dynamique de la combinaison des activités et des stratégies de médiation en cours de langue de spécialité avec des activités de traduction spécialisée en vue d'une amélioration de l'acquisition du lexique spécialisé. Soulignons tout d'abord que l'appellation « français de spécialité » recouvre, selon Mourlhon-Dallies [2008:71], un ensemble d'interventions consistant à enseigner le français en étroite relation avec un champ disciplinaire ou un secteur d'activité bien circonscrit et est utilisée en didactique du français langue étrangère. Cette appellation concerne aussi, selon l'auteure, les champs du français 
langue seconde et du français langue maternelle puisqu'au niveau des études supérieures, les étudiants natifs ou étrangers inscrits dans des cursus professionnalisants suivent les enseignements de français (langue maternelle ou étrangère et/ou seconde) qui forment une sorte de tronc commun disciplinaire et relèvent à ce titre du français de spécialité.

Par ailleurs, Springer [2014:13] parle de «balkanisation» de la didactique du FLE en différentes spécialités que l'on oppose à la langue générale (Français sur Objectifs Universitaires - FOU, Français sur Objectifs Spécifiques - FOS, Français Langue d'Intégration - FLI, Français Langue Professionnelle - FLP). Lorsqu'il se réfère au rôle du secteur LANSAD et des langues de spécialité, l'auteur souligne l'optique lexicale qui caractérise l'enseignement des langues aux publics à besoins particuliers. Plus particulièrement, il souligne que "l'enseignement de spécialité s'inscrit dans le cadre de l'anglais scientifique et technique. Il s'appuie sur la description de registres de langue spécifiques à des domaines scientifiques et académiques. Un registre n'est en fait qu'un inventaire de lexique spécialisé » [2014 : 14]. De même, selon Mourlhon-Dallies [2008 : 71], les enseignements de français plus haut mentionnés centrés sur le lexique spécialisé, la grammaire de spécialité, la maîtrise des actes de parole et la pratique des genres discursifs doivent être dispensés dès les premières années de spécialité, accompagnés tout au long des études par des données interculturelles et socio-historiques. Nous appuyant sur les auteurs susmentionnés, nous nous intéressons, à notre tour, au lexique en tant qu'élément le plus marquant de la communication spécialisée et qui dépasse largement celui de la langue usuelle étant ainsi capable « de saisir le monde cognitif de la spécialité dans sa complexité » (Kocourek [1991 : 41]).

Étant donné que les supports utilisés dans les deux cours sont des textes spécialisés dans lesquels le discours juridique s'entremêle avec le discours économique, nous partageons l'argumentation de Mangiante qui, en étudiant la place et le rôle du lexique spécialisé dans les discours de français commercial et économique [2002:27-39] soutient que, pour l'enseignement/apprentissage du lexique, s'avèrent indispensables la connaissance des aspects morphosyntaxiques de la langue cible ainsi que l'exploration des réalisations discursives. Nous avons donc essayé de donner une perspective à la fois sémantique et discursive à l'enseignement du lexique juridique et économique qui caractérisait les textes fournis aux étudiants. Pour faciliter l'acquisition du lexique spécialisé, nous avons établi des critères thématiques, sémantiques et morphosyntaxiques (Gaultier \& Masselin [1973]) que nous présenterons plus loin.

5 Dans un premier temps, nous analyserons le concept de médiation linguistique qui englobe une nouvelle conception élargie et intégrative des activités de traduction dans le cadre des nouvelles approches communicatives et actionnelles en didactique des langues, laquelle implique réduction et réécriture de texte. Nous considérons que la traduction pédagogique revêt un nouveau rôle, celui de la médiation, ce qui nous permettra de rapprocher les deux concepts. Notre hypothèse de travail est qu'au niveau didactique, les activités de médiation dans un cours de langue de spécialité fonctionnent en complémentarité avec le cours de traduction spécialisée renforçant la compréhension et l'acquisition du lexique spécialisé.

6 Dans un deuxième temps, nous présenterons notre expérience menée avec deux groupes d'étudiants dans le cadre de quatre modules enseignés au sixième semestre d'études d'un Département de gestion, parcours LEA. Ces quatre modules, dont deux de langue de spécialité et deux de traduction spécialisée, impliquent deux langues étrangères de la façon suivante : « Négociations en milieu professionnel - langue française », « Traduction 
juridique français-grec », "Négociations en milieu professionnel - langue italienne », « Traduction juridique italien-grec ».

7 Nous commencerons par présenter un bref aperçu du rôle de la traduction pédagogique en didactique des langues afin de nous concentrer sur la médiation linguistique en tant qu'activité langagière dont le rôle est mis en valeur dans la deuxième version du CECR.

\section{De la traduction pédagogique à la médiation : le passage à une pratique (extra)ordinaire?}

8 La réhabilitation de la traduction dite didactique ou pédagogique (Ladmiral [1972] ; Puren [1995] ; Besse [1998]) en didactique des langues se fait au tournant du XXe siècle après de longues périodes au cours desquelles des approches didactiques se sont développées telle la méthodologie traditionnelle (grammaire-traduction), la méthodologie directe, la méthodologie audio-orale/audiovisuelle. Ces méthodes se sont intéressées soit à l'exercice de la traduction de la langue maternelle en langue étrangère, visant à la fois l'application correcte de la règle de grammaire enseignée et la vérification de l'acquisition du vocabulaire établi, soit à l'interdiction de tout recours à la L1, et donc à la traduction. Certains ont jugé qu'un tel apprentissage était peu efficace, ou monolingue (Puren [1988, 1995]). En outre, l'approche communicative dans les années 1970 a surtout privilégié le dialogue et l'interaction, sans pour autant écarter la traduction puisqu'une telle approche «accepte la traduction en L1, quand celle-ci s'avère possible (le maître connaît cette L1 et elle est commune en cours) » (Besse [2004:46]). De son côté, Arroyo, partageant l'idée de Lado [1957] (cité dans Arroyo [2008]) sur la place de la traduction dans l'enseignement des langues, signale que la traduction pourrait faire « apparaître les signifiants correspondants aux signifiants de la langue maternelle de l'apprenant et lui faire comprendre que les signifiés auxquels il renvoie, ne se recoupent qu'approximativement ».

9 Cependant, avec l'approche actionnelle proposée dans le CECR, nous constatons le passage du paradigme de la communication à celui de l'action: l'approche consiste à rendre l'apprenant un acteur social, non seulement capable de parler avec l'autre, mais aussi d'agir avec l'autre pendant le temps de son apprentissage, en lui proposant des occasions de "co-actions» comme des actions communes à finalité collective (Puren [2002]). Il s'agit également d'utiliser cette langue dans une autre société et de prendre en considération la diversité culturelle en mettant en œuvre les composantes linguistique, sociolinguistique et pragmatique de la langue dans des contextes et des conditions variés.

Ainsi, en raison des changements sociaux mondiaux, les objectifs de l'enseignement et de l'apprentissage des langues étrangères ont-ils considérablement changé et la formation à l'interculturalité s'ajoute à celle du plurilinguisme : le modèle du « locuteur natif » a été remplacé par celui du «locuteur interculturel» capable de communiquer des informations et d'entretenir des relations avec des personnes parlant d'autres langues et appartenant à d'autres cultures (Byram et al. [2002: 7]). Faisant suite à ces changements, la notion de compétence linguistique a subi des révisions majeures. Selon Kramsch [2006:103], la compétence linguistique avancée aujourd'hui devrait se référer à «la capacité de traduire, de transposer et de réfléchir de manière critique sur les significations sociales, culturelles et historiques véhiculées par la grammaire et le lexique $»$. 
11 Coste \& Cavalli [2015:11] expliquent que la pluralité linguistique et culturelle ne constitue pas l'aboutissement du parcours de l'acteur social (de l'enfant à proprement parler) mais comme en étant déjà à l'origine. Ils soutiennent que «l'enfant qui arrive à l'école a déjà, qu'il en soit conscient ou non, l'expérience et une certaine pratique de la diversité linguistique et culturelle. C'est un acteur social en devenir - au répertoire plurilangagier et pluriculturel - qui est scolarisé ».

Étant donné que des cultures différentes communiquent entre elles à un rythme croissant, la question de la traduction, notamment en cours de langue étrangère de spécialité, bénéficie d'un intérêt renouvelé, en particulier par ceux qui recherchent différents aspects de la communication linguistique et interculturelle. Puren déjà en 2002 considère que :

toute classe de langue constitue en tant que telle un certain cadre co-actionnel-coculturel puisque l'enseignant et les apprenants ont à y réaliser une action conjointe d'enseignement/apprentissage d'une langue-culture qu'ils ne pourront mener à bien ensemble que sur la base d'un minimum de conceptions communes,

étant donné que les actes de parole eux-mêmes n'ont de signification que par rapport aux actions sociales qu'ils concourent à réaliser. Les conceptions partagées qui seront mobilisées dans les actions sociales ouvrent la voie, selon Puren, à des formes diversifiées de traduction que les auteurs du CECR attribuent à l'activité de médiation. Ces formes proposées par les auteurs du CECR font appel à l'interlangue, c'est-à-dire la traduction, l'interprétation simultanée ou consécutive, en même temps qu'à l'intralangue, à savoir, le résumé, la synthèse, le compte rendu, la reformulation [2001:18] que nous présenterons un peu plus loin.

Les travaux qui portent sur le rôle de la traduction communicative en didactique des langues concernent les véritables besoins et actes communicatifs des apprenants et explorent une multitude d'activités de traduction alternatives (Duff [1989] ; Puren [1995] ; Schäffner [1998] ; Nord [2005] ; Carreres [2006] ; Liao [2006] ; House [2009]; Cook [2010]; Randaccio [2012] ; Peverati [2013] ; Károly [2014] ; Fernandez-Guerra [2014]). Les études ou travaux menés mettent l'accent sur le rôle de la traduction dans le développement de la compétence linguistique, communicative et interculturelle des apprenants tout en reconnaissant plusieurs aspects positifs: meilleure compréhension de la L2 et du fonctionnement général des langues, réduction du stress lié à l'apprentissage, développement des stratégies de lecture, de compréhension et de comparaison des deux systèmes linguistiques, meilleure mémorisation des phénomènes idiomatiques des langues, meilleure (auto-)évaluation des apprenants, acquisition et transmission de connaissances culturelles et de valeurs sociales.

15 Étant donné que la conception de la médiation linguistique telle qu'elle est proposée par le CECR version 2016 comporte les descripteurs des échelles de compétences, nous jugeons indispensable de procéder à une comparaison entre la première version, celle de 2001, et celle de 2016.

\subsection{CECR : les deux versions}

16 Les auteurs du CECR déclarent :

dans les activités de médiation, l'utilisateur de la langue n'a pas à exprimer sa pensée mais doit simplement jouer le rôle d'intermédiaire entre des interlocuteurs incapables de se comprendre en direct. Il s'agit habituellement (mais non 
exclusivement) de locuteurs de langues différentes. Parmi les activités de médiation, on trouve l'interprétation (orale) et la traduction (écrite), ainsi que le résumé et la reformulation de textes dans la même langue lorsque le texte original est incompréhensible pour son destinataire. [2001 : 71]

17 La médiation devient ainsi une compétence complexe à des fins de transmission d'un contenu. Ce qu'il faut prendre en considération sont les variables des capacités (de la réception de l'oral ou de l'écrit vers la production orale ou écrite) et les variables des tâches. Dans le manuel développé par la Division des politiques linguistiques du Conseil de l'Europe [2009: 171] dans le but de relier les examens de langues au CECR, les activités de médiation mettent en évidence les capacités dans la langue étrangère. Ces activités s'effectuent :
(a) à partir de la langue étrangère vers la langue maternelle (capacités du domaine de la réception),
(b) à partir de la langue maternelle vers la langue étrangère (capacités du domaine de la production),
(c) dans une langue étrangère, et
(d) d'une langue étrangère à une autre (dans les deux derniers cas, on fait appel à la fois à la réception et à la production).

Dans la section 4.6.3 du CECR [2001:78] les activités langagières de médiation schématisent deux situations, celle de la traduction et celle de l'interprétation. De plus, sont proposées des activités pour lesquelles les apprenants doivent produire une réponse textuelle à un stimulus textuel lequel peut être un ensemble de consignes écrites, une question orale, un texte discursif authentique ou fabriqué ou une combinaison de ces derniers. Les apprenants doivent produire un texte oral ou écrit en L1 ou en L2. Pourtant, la version de 2001 ne prévoit pas d'échelles de descripteurs pour la médiation. En 2016, North et Piccardo publient un projet de l'Unité des Politiques Linguistiques du Conseil de l'Europe (UPL) mené entre janvier 2014 et avril 2016 dont l'objectif principal est la conception d'un système descriptif ainsi que de descripteurs pour illustrer la médiation. Comme ils le soulignent [2016:8], la médiation est associée le plus souvent à une médiation interlinguistique (transmettre une information réduite à une sorte de traduction ou d'interprétation) sans pour autant perdre sa dimension intralinguistique qui peut concerner la langue cible ou la langue maternelle «lorsque l'apprenant/ utilisateur vise à donner du sens au texte (écrit ou oral) auquel il est confronté" (Piccardo [2012 : 292]).

Il s'agit ici du premier des quatre types de médiation présents dans le CECR, celui de la médiation linguistique. Les trois autres sont la médiation culturelle, la médiation sociale et la médiation pédagogique (North \& Piccardo [2016:8-11]). Quand on passe d'une langue à l'autre, on passe d'une culture à l'autre (CECR [2001:40,83]), on joue un rôle social actif, celui d'intermédiaire entre différents interlocuteurs essayant de (re)formuler un texte ou de (re)construire le sens d'un message. Enfin, quant à la médiation pédagogique, elle englobe la médiation cognitive et la médiation relationnelle: elle facilite l'accès au savoir, elle encourage les utilisateurs/apprenants à élaborer leur réflexion, à établir des relations et des échanges, à coopérer et à résoudre des problèmes. Ces quatre types impliquent des compétences et habiletés linguistico-communicatives, interactionnelles, stratégico-méthodiques et interculturelles (Hallet [2008] cité par Biedermann [2014: 85]). 
20 Par ailleurs, Coste \& Cavalli [2015 : 29] distinguent la médiation cognitive de la médiation relationnelle après avoir expérimenté les quatre types mentionnés ci-dessus. Ils considèrent que la médiation cognitive est un processus qui facilite l'accès aux connaissances et aux concepts.

21 Par médiation, on désigne toute opération, tout dispositif, toute intervention qui, dans un contexte social donné, vise à réduire la distance entre deux (voire plus de deux) pôles altéritaires qui se trouvent en tension l'un par rapport à l'autre [2015 : 28]. Le terme de «tension" prend le sens de « on s'approche de " tandis que les pôles concernent d'une part, les acteurs sociaux et, d'autre part des formes et types d'altérité, à savoir des cultures différentes, des valeurs « étrangères », des connaissances nouvelles.

De plus, le CECR reconnaît la traduction comme élément constitutif de la compétence communicative de l'apprenant et comme expression de la compétence de médiation de l'apprenant. Pym et al. [2013:6] la considèrent comme une cinquième compétence fondamentale favorisant la compétence d'intercompréhension, c'est-à-dire la capacité de comprendre et d'interagir en utilisant des structures communes à plusieurs langues. Ils soutiennent que «le terme 'traduction' inclut principalement la réception et / ou la production et / ou le travail sur des textes parallèles oraux ou écrits (discours appariés en deux langues) en classe » [2013:13]. Ceci comprend: a) l'interprétation simultanée, où tout dit dans une langue est traduit dans l'autre, habituellement par le professeur ; b) un aperçu dans les deux langues; et c) la traduction communicative et l'interprétation de dialogue par les apprenants (de plus en plus conceptualisées sous forme de « médiation »).

Compte tenu de ce qui précède, nous estimons que l'introduction de la médiation linguistique en tant qu'aspect de la traduction pédagogique constitue une approche progressive et différenciée des activités de traduction et revisite le rôle de la traduction en didactique des langues. C'est dans ce sens que nous devons faire référence à la littérature produite sur le concept de médiation en citant les travaux de Byram [2008], de Aden [2012], de Weissmann [2012], de Biedermann [2014], de Franić [2014], de Chovancová [2016], de Medioni et al. [2016] qui interrogent le rôle de la médiation et de la traduction en cours de langue et comportent des exemples d'activités de médiation proposées ou réalisées.

24 Nous procédons maintenant à la description de notre expérience en cours de langue et de traduction spécialisée afin de montrer que la médiation linguistique constitue une activité aussi bien innovante qu'efficace dans l'enseignement du lexique spécialisé.

\section{Description de l'expérience}

Nous présentons une proposition didactique dont l'objectif est de mettre en valeur l'intégration de la médiation linguistique en cours de langue de spécialité. Cette proposition s'est appuyée sur une expérience exploratoire qui impliquait deux groupes d'étudiants apprenant le français ou l'italien et qui, par le biais des tâches de médiation linguistique, devaient transmettre en langue maternelle des informations prises dans des textes spécialisés (français ou italien) à leur pair/interlocuteur qui n'avait pas accès au contenu. Les tâches comportaient la présentation orale entre pairs du résumé de textes juridiques, la recherche d'équivalences au niveau du lexique spécialisé (français-grec, italien-grec) et enfin, à partir de ces équivalences, la création d'un glossaire trilingue 
spécialisé en travail collaboratif. Ces mêmes groupes suivaient les cours de traduction spécialisée (français-grec, italien-grec) et avaient comme tâche la traduction de textes juridiques impliquant le repérage de termes juridiques et économiques ainsi que la recherche d'équivalents. À cet effet, des groupes expérimentaux et des groupes témoins ont été créés (voir introduction). Notre hypothèse de travail était que l'enseignement de la langue de spécialité avec médiation linguistique favoriserait l'acquisition du lexique spécialisé, ce qui aurait un impact également positif sur les performances des étudiants aussi bien en langue (production orale notamment) qu'en traduction spécialisée.

Concernant la documentation utilisée, aussi bien en cours de langue qu'en traduction, les étudiants devaient traiter des documents multimodaux (textes écrits, vidéos, graphiques) de nature juridique, puisés dans des sites officiels d'institutions et d'organismes, concernant le recrutement, les types de contrat de travail, les conventions de travail, les types de rémunération, les différents congés ainsi que la négociation collective, la fusion d'entreprises et les droits des salariés.

Au niveau méthodologique, l'approche actionnelle préconisée par le CECR et la théorie interprétative nous ont servi de supports de réflexion pour les raisons suivantes. Tout d'abord, l'approche actionnelle a pour objectif de faire de l'apprenant un acteur social, compétent et expérimenté. Elle consiste à exposer l'apprenant à des scénarios portant sur des situations variées de la vie professionnelle : dans notre cas, des mono-tâches (Nissen [2011]) devaient être intégrées à la thématique du cours de langue de spécialité en simulant ainsi une situation communicative réaliste par l'utilisation de documents authentiques et dans le but de faciliter l'accès au savoir par les pairs grâce au processus de médiation. En second lieu, dans la théorie interprétative, l'apprenant assiste à une opération complexe de compréhension, de déverbalisation et de reconstruction de sens, en somme il participe à un acte de communication médiateur entre deux situations linguistiques porteuses des réalités socioculturelles différentes (Lavault [1998:79-95]; Seleskovitch \& Lederer [2001]). Piccardo se réfère aussi bien à une médiation sociale interpersonnelle qu'à une médiation intrapersonnelle, « où l'apprenant/utilisateur vise à donner du sens au texte (écrit ou oral) auquel il est confronté. Cette activité est, elle aussi, sociale car elle met en relation un scripteur avec un lecteur, un locuteur avec un auditeur » [2012: 292]. Bien qu'il soit plus facile de jouer le rôle de médiateur de la langue étrangère vers la langue maternelle, nous croyons que ce type d'activité devrait d'abord impliquer un travail sur le message, sur sa fonction et son organisation discursive, fondé sur la connaissance que l'apprenant a d'un même message dans sa langue maternelle, puis l'entraînement de l'apprenant à interpréter ce message lu ou entendu. Il va de soi qu'aussi bien en cours de langue qu'en cours de traduction spécialisée, le travail sur le lexique tenait compte des critères suivants :

a) thématiques : le lexique relevait des domaines juridique et économique,

b) sémantiques: le lexique spécialisé était exploré d'un point de vue conceptuel (synonymie, antonymie et hypéronymie),

c) morpho-syntaxiques: dérivation par affixation et dérivation syntagmatique.

Les étudiants qui ont participé à l'expérience étaient au nombre de 38, dont 20 en italien et 18 en français. Leur niveau correspondait à $\mathrm{B} 1+$ et ils ont été répartis en groupes expérimentaux et en groupes témoins de la façon suivante : 
(a) cours de langue avec médiation: neuf en français et dix en italien (expérimentaux),

(b) cours de langue sans médiation: neuf en français et dix en italien

(témoins),

(c) cours de traduction : 18 en français et 20 en italien. prétests dans les deux cours (langue et traduction) ainsi que des questionnaires d'autoévaluation (voir annexe 1 pour la langue, et annexe 3 pour la traduction). Nous avons demandé à chaque paire (un étudiant en français en tandem avec un étudiant en italien) de résumer oralement respectivement un texte français ou italien en grec dans le but de médier réciproquement le contenu en tenant compte de la composante pragmatique de celui-ci. La même épreuve a été prévue en tant que post-test en fin de semestre. De plus, le même questionnaire a été utilisé par les professeurs en tant que questionnaire d'évaluation des étudiants en début et en fin de semestre. Dans le même esprit, aussi bien en prétest qu'en post-test, nous avons proposé aux étudiants à travers quatre exercices une liste de dix termes juridiques alternativement en français et en italien parmi ceux étudiés durant le semestre, en leur demandant de trouver les équivalents grecs au moyen de la reconnaissance éventuelle de la langue romane proposée. Ensuite, ils ont été invités à répondre à trois questions sur l'éventuel impact positif de la langue romane sur la recherche d'équivalents (voir annexes 2.1, 2.2). Nous commenterons les résultats de ces tests un peu plus loin.

Les catégories d'échelles de descripteurs qui nous ont paru les plus appropriés pour les objectifs de notre expérience et suivant lesquels nous avons étudié les compétences des étudiants concernaient des activités de médiation cognitive ainsi que des stratégies de 
médiation. Les stratégies présentées sont des stratégies de performance, c'est-à-dire des façons d'aider les pairs à comprendre, au cours du processus de médiation. Elles portent sur la façon de traiter le contenu source à l'intention du destinataire. Nous avons écarté certaines activités des catégories d'échelles jugeant qu'elles ne répondaient pas aux situations de communication dans notre cours. Pour être plus précis, nous renvoyons le lecteur au tableau ci-après (tableau 1) proposé par North \& Piccardo [2016 : 23-24] adapté à nos besoins :

Tableau 1 : Descripteurs illustrant les activités de médiation (North \& Piccardo [2016 : 23-24])

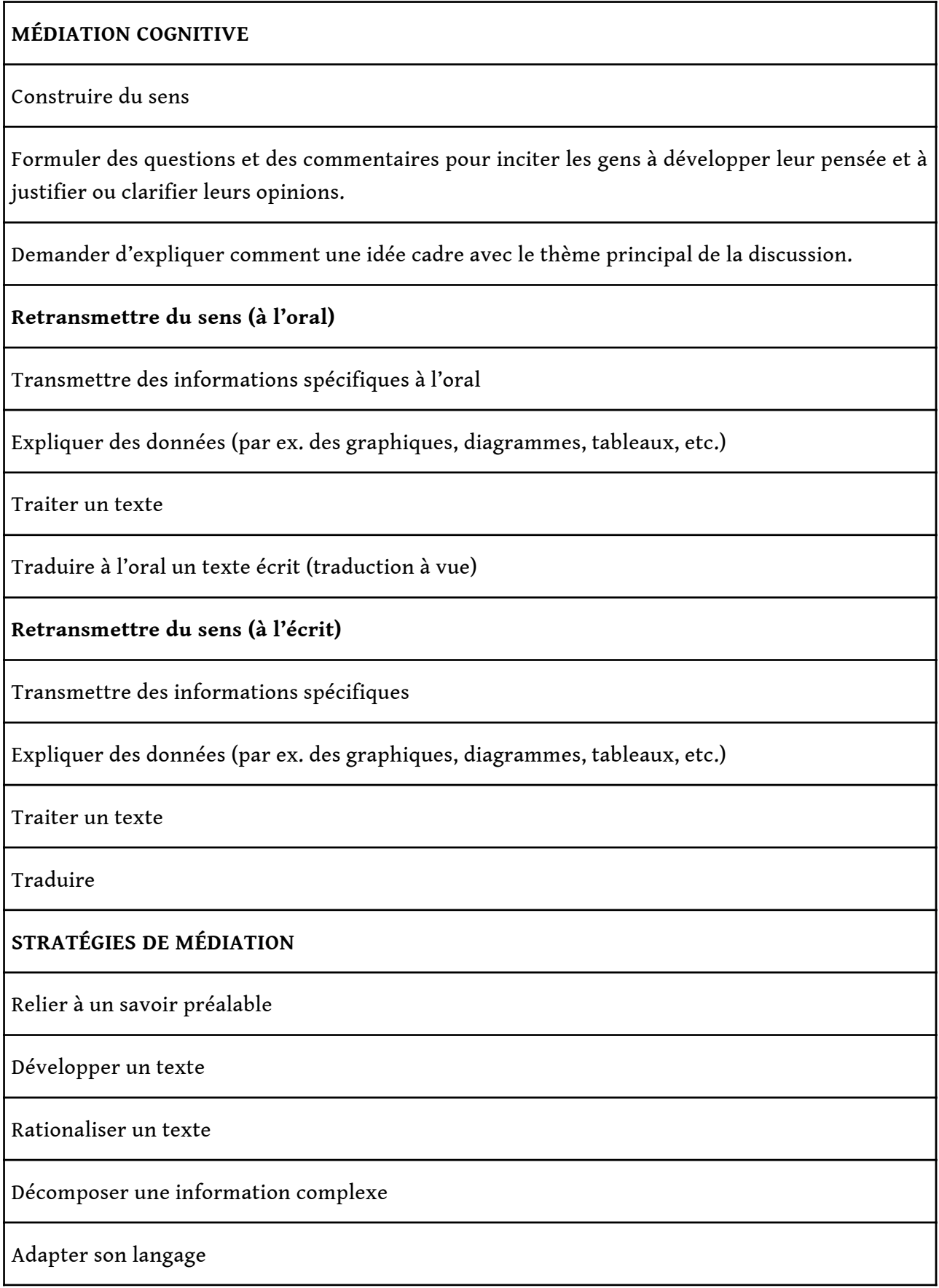


Pour mener à bien les activités de médiation, les étudiants ont dû suivre des instructions concernant la retransmission du sens en se concentrant sur des informations spécifiques sans dévier de l'original, la reformulation adéquate de l'original tout en tenant compte des particularités culturelles des deux langues impliquées. Parmi les stratégies proposées par l'enseignant, les étudiants ont procédé au surlignage des passages importants, à la recherche de termes-clés, à la prise de notes, à la restitution des informations selon leur pertinence.

Pour ce qui est de la traduction spécialisée, au début du semestre en tant que prétest chaque groupe a été invité à traduire un texte juridique de 400 mots environ (français ou italien vers le grec) sur la thématique mentionnée plus haut. Les étudiants n'avaient aucun moyen à leur disposition et, en plus de la traduction, ils ont dû constituer un glossaire bilingue à partir des termes du texte source. Le même texte a été proposé comme épreuve de post-test avec les mêmes consignes. L'objectif de ces deux examens était de vérifier si, grâce aux cours de langue avec médiation, leurs compétences de repérage de termes en langue source et de leur traduction en langue cible avaient été améliorées. Durant le semestre, le cours s'est déroulé de la façon habituelle : les étudiants traduisaient des textes à l'aide des moyens électroniques, tels des mémoires de traduction, des dictionnaires en ligne, des textes parallèles et comparables. Ils ont en outre dû présenter oralement un devoir de traduction d'un texte de 1000 mots environ suivi d'un glossaire.

36 Nous allons maintenant présenter et analyser les données recueillies des questionnaires distribués aux étudiants et aux enseignants.

\subsection{Observation des pratiques étudiantes - Résultats des questionnaires}

\subsubsection{Compétences des étudiants en médiation cognitive}

(a) Graphiques de médiation cognitive

Les figures 1.1 et 1.2 présentent les performances des étudiants avec ou sans médiation. 


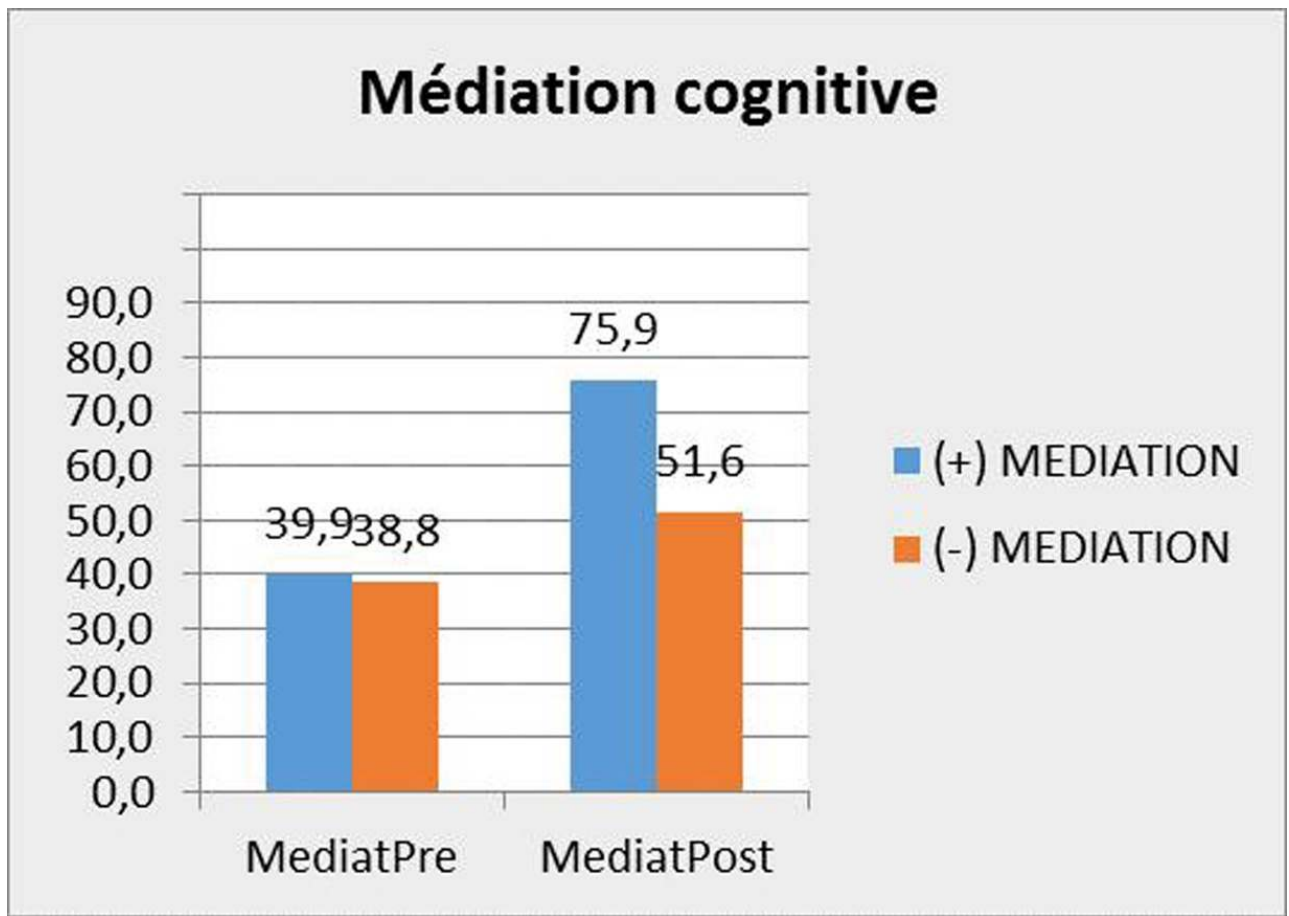

Figure 1.2: Médiation cognitive en langue italienne (14 items, échelle : 0-90)

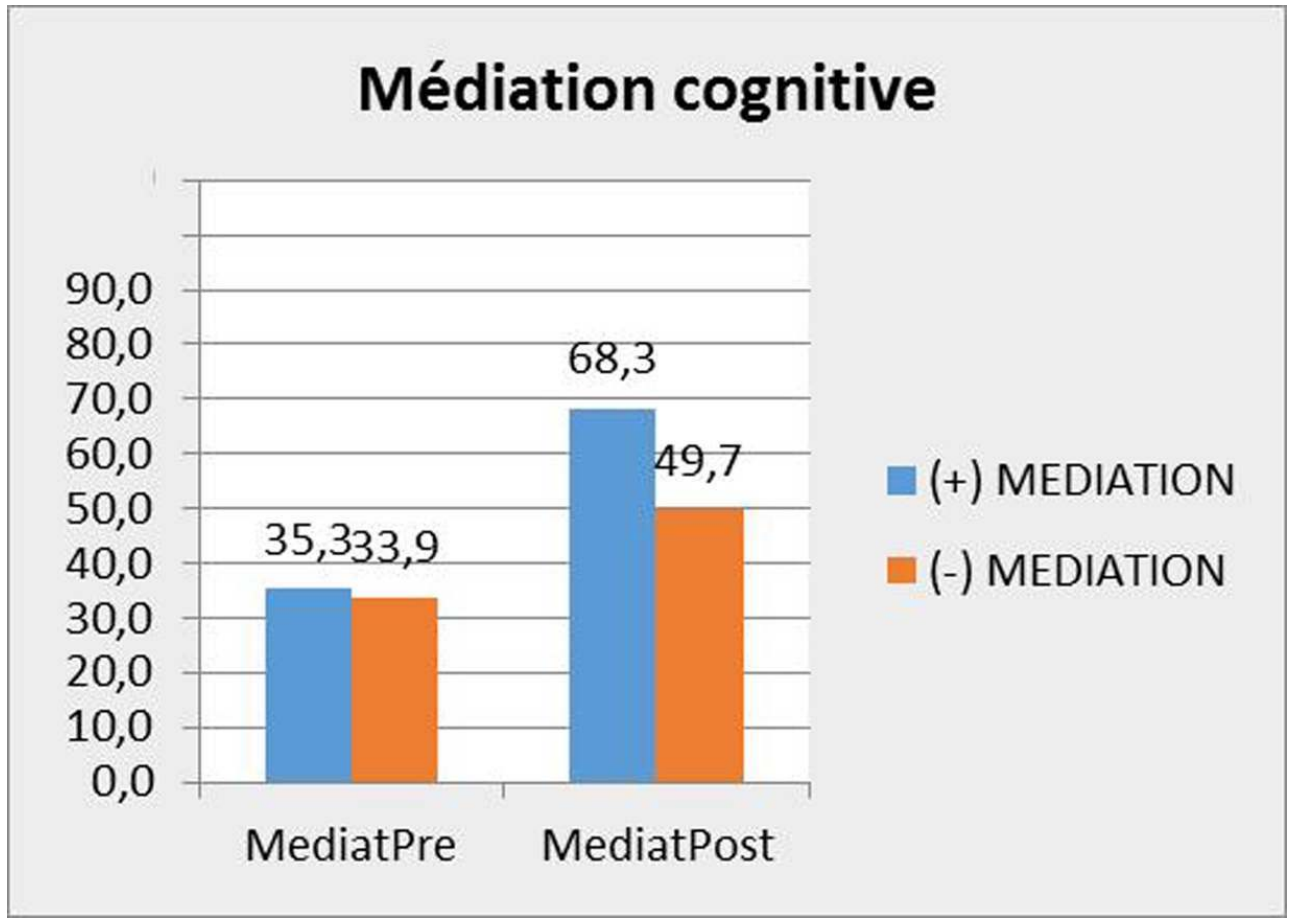

Chaque barre du graphique correspond à une moyenne. Plus spécifiquement, les deux barres de gauche représentent les moyennes de performance des étudiants avec (+) et sans (-) médiation en début de semestre telles qu'elles résultent de l'addition des réponses sur l'échelle de Likert (pas du tout [0] - beaucoup [5]) aux questions du questionnaire d'autoévaluation; les deux barres de droite correspondent aux moyennes 
de performance avec (+) et sans (-) médiation en fin de semestre telles qu'elles résultent de l'addition des réponses sur l'échelle de Likert aux mêmes questions. Pour ce qui est du français, nous constatons une nette amélioration de la performance des étudiants ayant suivi le cours de langue avec médiation (de 39,9 à 75,9, donc une augmentation de 36,0) contre une hausse beaucoup plus faible pour le groupe témoin (de 38,8 à 51,6, une augmentation de 12,8), le groupe expérimental bénéficiant d'une différence de moyennes entre les deux groupes de l'ordre de 23,2.

Pour ce qui est de l'italien, nous observons exactement la même tendance. Pour les étudiants ayant suivi le cours de langue avec médiation la performance s'est notablement améliorée (de 35,3 à 68,3, donc une augmentation de 33,0) contre une hausse beaucoup moins importante pour le groupe témoin (de 33,9 à 49,7, une augmentation de 15,8), la différence des moyennes entre les deux groupes étant 17,2 en faveur du groupe expérimental.

(b) Graphiques de stratégies de médiation

Les figures 2.1 et 2.2 présentent deux graphiques qui correspondent au recours des étudiants à des stratégies de médiation.

Figure 2.1 : Stratégies de médiation en langue française (8 items, échelle : 0-40)

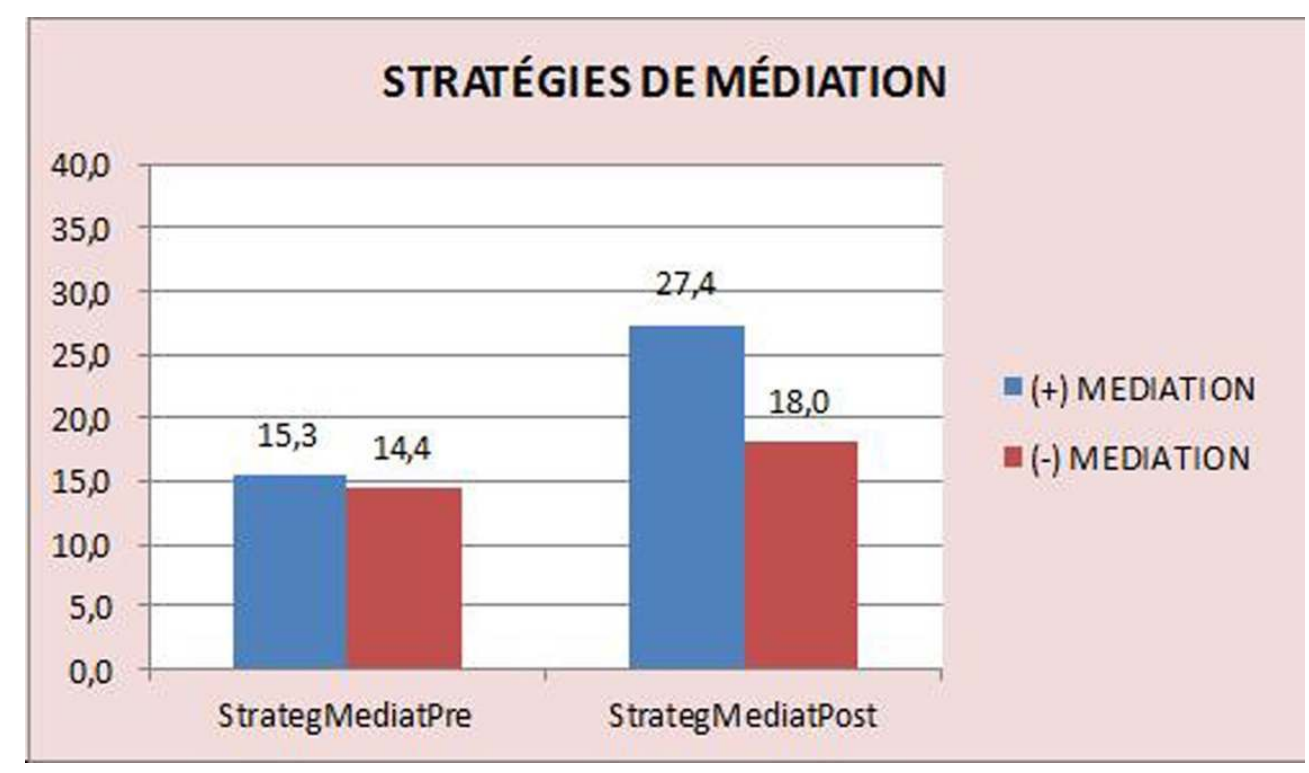


Figure 2.2 : Stratégies de médiation en langue italienne (8 items, échelle : 0-40)

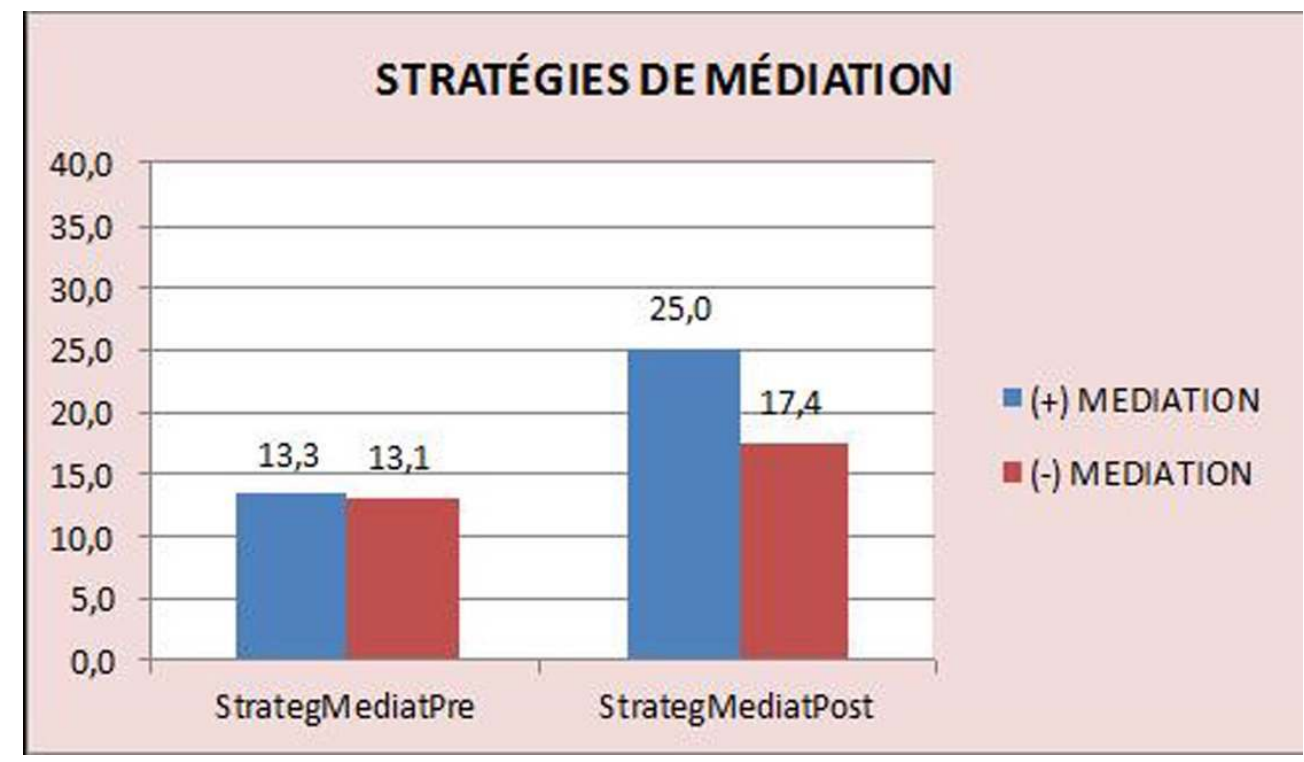

Plus concrètement, en français nous voyons que les étudiants du groupe expérimental se considèrent bien plus à l'aise avec ces stratégies en fin de semestre que leurs pairs du groupe témoin (avec médiation, de 15,3 à 27,4 donc une hausse de 12,1; sans médiation, de 14,4 à 18,0 donc une augmentation de 3,6). Au total, le groupe expérimental l'emporte sur le groupe témoin avec une différence de l'ordre de 8,5.

Il en est de même de la langue italienne. Les étudiants du groupe expérimental croient employer ces stratégies avec plus d'aisance en fin de semestre que leurs pairs du groupe témoin (avec médiation, de 13,3 à 25,0 donc une augmentation de 11,7; sans médiation, de 13,1 à 17,4 donc une hausse de 4,3). Au total, il y a une différence de 8,6 en faveur du groupe expérimental.

Dans le tableau 2, nous regroupons les résultats d'autoévaluation des étudiants dans les deux langues étrangères de spécialité avec toutes les composantes aussi bien de la médiation cognitive que des stratégies de médiation. Ces résultats montrent une nette amélioration de la performance des étudiants qui ont suivi le cours de langue avec médiation. Les moyennes des groupes ayant suivi les cours de langue de spécialité avec médiation sont en gras.

Tableau 2 : Récapitulatif des moyennes et des différences indiquant l'amélioration en médiation (autoévaluation des étudiants)

\begin{tabular}{|l|l|l|l|l|l|l|l|}
\hline & & \multicolumn{3}{|l|}{ Langue française } & \multicolumn{2}{|l|}{ Langue italienne } \\
\hline & groupes & prétest & $\begin{array}{l}\text { post- } \\
\text { test }\end{array}$ & hausse & prétest & $\begin{array}{l}\text { post- } \\
\text { test }\end{array}$ & hausse \\
\hline \multirow{3}{*}{ Médiation Cognitive } & $\begin{array}{l}(+) \\
\text { médiation }\end{array}$ & 39,9 & 75,9 & $\mathbf{3 6 , 0}$ & 35,3 & 68,3 & $\mathbf{3 3 , 0}$ \\
\cline { 2 - 8 } & $\begin{array}{l}(-) \\
\text { médiation }\end{array}$ & 38,8 & 51,6 & 12,8 & 33,9 & 49,7 & 15,8 \\
\hline
\end{tabular}




\begin{tabular}{|c|c|c|c|c|c|c|c|}
\hline \multirow{2}{*}{ Construire du sens } & $\begin{array}{l}(+) \\
\text { médiation }\end{array}$ & 3,8 & 7,2 & 3,4 & 3,4 & 5,9 & 2,5 \\
\hline & $\begin{array}{l}(-) \\
\text { médiation }\end{array}$ & 3,2 & 4,7 & 1,5 & 3,1 & 4,3 & 1,2 \\
\hline \multirow{2}{*}{ Retransmettre du sens (à l'oral) } & $\begin{array}{l}(+) \\
\text { médiation }\end{array}$ & 5,3 & 12,2 & 6,9 & 4,4 & 9,8 & 5,4 \\
\hline & $\begin{array}{l}(-) \\
\text { médiation }\end{array}$ & 5,6 & 8,0 & 2,4 & 4,3 & 8,1 & 3,8 \\
\hline \multirow{2}{*}{$\begin{array}{l}\text { expliquer des données à l'oral } \\
\text { (graphiques, diagrammes, etc.) }\end{array}$} & $\begin{array}{l}(+) \\
\text { médiation }\end{array}$ & 3,2 & 6,8 & 3,6 & 2,9 & 6,1 & 3,2 \\
\hline & $\begin{array}{l}(-) \\
\text { médiation }\end{array}$ & 3,6 & 5,1 & 1,5 & 2,5 & 4,6 & 2,1 \\
\hline \multirow{2}{*}{ traiter un texte à l'oral } & $\begin{array}{l}(+) \\
\text { médiation }\end{array}$ & 10,6 & 19,4 & 8,8 & 9,7 & 18,7 & 9 \\
\hline & $\begin{array}{l}(-) \\
\text { médiation }\end{array}$ & 10,3 & 13,7 & 3,4 & 9,6 & 13,4 & 3,8 \\
\hline \multirow{2}{*}{$\begin{array}{l}\text { traduire à l'oral un texte écrit } \\
\text { (traduction à vue) }\end{array}$} & $\begin{array}{l}(+) \\
\text { médiation }\end{array}$ & 1,7 & 2,8 & 1,1 & 1,6 & 2,8 & 1,2 \\
\hline & $\begin{array}{l}(-) \\
\text { médiation }\end{array}$ & 1,7 & 2,1 & 0,4 & 1,3 & 1,9 & 0,6 \\
\hline \multirow{2}{*}{ Stratégies de Médiation } & $\begin{array}{l}(+) \\
\text { médiation }\end{array}$ & 15,3 & 27,4 & 12,1 & 13,3 & 25,0 & 11,7 \\
\hline & $\begin{array}{l}(-) \\
\text { médiation }\end{array}$ & 14,4 & 18,0 & 3,6 & 13,1 & 17,4 & 4,3 \\
\hline \multirow{2}{*}{ relier à un savoir préalable } & $\begin{array}{l}(+) \\
\text { médiation }\end{array}$ & 2,2 & 3,3 & 1,1 & 2,3 & 3,5 & 1,2 \\
\hline & $\begin{array}{l}(-) \\
\text { médiation }\end{array}$ & 1,9 & 2,2 & 0,3 & 1,9 & 2,3 & 0,4 \\
\hline \multirow{2}{*}{ développer un texte } & $\begin{array}{l}(+) \\
\text { médiation }\end{array}$ & 5,3 & 9,7 & 4,4 & 4,8 & 9,3 & 4,5 \\
\hline & $\begin{array}{l}(-) \\
\text { médiation }\end{array}$ & 5,7 & 6,7 & 1,0 & 5,0 & 6,8 & 1,8 \\
\hline & $\begin{array}{l}(+) \\
\text { médiation }\end{array}$ & 4,4 & 7,8 & 3,4 & 3,3 & 6,4 & 3,1 \\
\hline
\end{tabular}




\begin{tabular}{|l|l|l|l|l|l|l|l|}
\cline { 2 - 9 } & $\begin{array}{l}(-) \\
\text { médiation }\end{array}$ & 3,9 & 4,9 & 1,0 & 3,2 & 4,3 & 1,1 \\
\hline \multirow{2}{*}{$\begin{array}{l}\text { décomposer une information } \\
\text { complexe }\end{array}$} & $\begin{array}{l}(+) \\
\text { médiation }\end{array}$ & 1,7 & 3,6 & $\mathbf{1 , 9}$ & 1,5 & 3,1 & $\mathbf{1 , 6}$ \\
\cline { 2 - 9 } & $\begin{array}{l}(-) \\
\text { médiation }\end{array}$ & 1,6 & 2,1 & 0,5 & 1,5 & 2,1 & 0,6 \\
\hline \multirow{2}{*}{ adapter son langage } & $\begin{array}{l}(+) \\
\text { médiation }\end{array}$ & 1,7 & 3,1 & $\mathbf{1 , 4}$ & 1,4 & 2,7 & $\mathbf{1 , 3}$ \\
\cline { 2 - 9 } & $\begin{array}{l}(-) \\
\text { médiation }\end{array}$ & 1,4 & 2,1 & 0,7 & 1,5 & 1,9 & 0,4 \\
\hline
\end{tabular}

Nous souhaiterions attirer l'attention du lecteur notamment sur la transmission d'informations spécifiques à l'oral (Qs : B1, B2, B3) et sur le traitement d'un texte à l'oral (Qs : D1, D2, D3, D4, D5, D6) dont les résultats illustrent l'impact positif de la médiation cognitive en cours de langue tant en français qu'en italien.

Il en est de même pour les stratégies de médiation. En matière de développement de texte (Qs: G1, G2, G3), nous observons une différence de moyennes de l'ordre de 4,4 pour le groupe expérimental de français et une différence également importante de l'ordre de 4,5 pour l'italien, donc une nette amélioration. De plus, pour ce qui est de la rationalisation d'un texte (Qs : H1, H2), l'augmentation est 3,4 pour le groupe témoin en français et 3,1 pour le groupe témoin en italien.

\subsubsection{Résultats des questionnaires d'évaluation des étudiants par les enseignants}

(a) Graphiques médiation cognitive

Les graphiques des figures 3.1 et 3.2 reflètent les moyennes des paramètres respectifs cités au tableau 1 qui correspondent à des questions du questionnaire complété par les enseignants concernant les performances des étudiants lors du prétest (barres de gauche) et lors du post-test (barres de droite). 


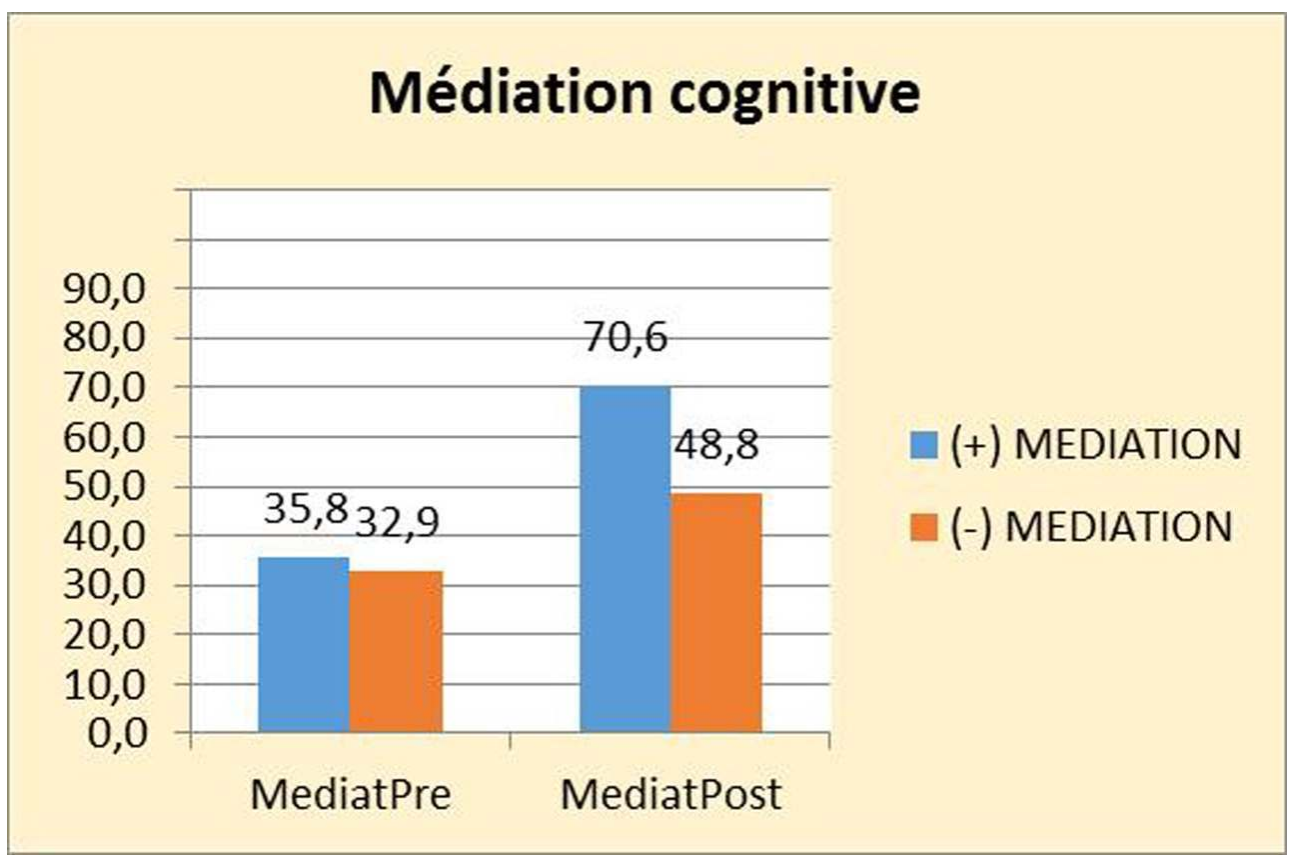

Figure 3.2: Médiation cognitive en langue italienne (14 items, échelle : 0-90)

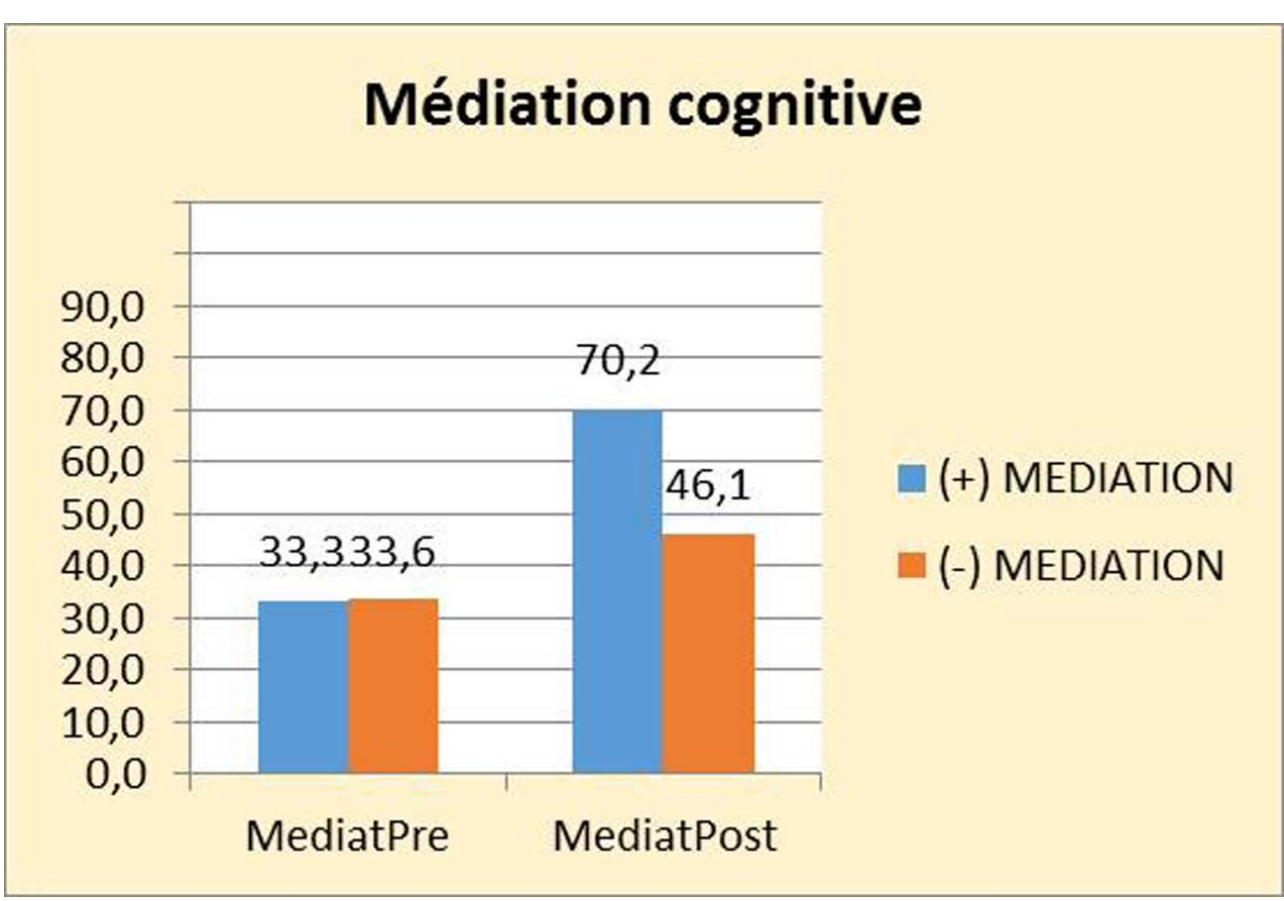

47 En langue française, nous constatons une nette amélioration pour les étudiants grâce à la médiation (de 35,8 à 70,6, donc une augmentation de 34,8) alors que le groupe témoin fait preuve d'un progrès plus lent (de 32,9 à 48,8, une augmentation de 15,9), la différence des moyennes entre les deux groupes étant 18,9 .

Pour ce qui est de l'italien, nous observons exactement la même tendance. Pour les étudiants ayant suivi le cours de langue avec médiation (de 33,3 à 70,2, donc une augmentation de 36,9 ) contre une hausse beaucoup plus faible pour le groupe témoin (de 
33,6 à 46,1, une augmentation de 12,5), la différence des moyennes entre les deux groupes étant 24,4 en faveur du groupe expérimental.

(b) Graphiques stratégies de médiation

Les figures 4.1 et 4.2 comportent des graphiques qui correspondent aux moyennes des paramètres respectifs cités au tableau 1 concernant les stratégies de médiation telles qu'elles ont été perçues par les enseignants.

Figure 4.1 : Stratégies de médiation en langue française (8 items, échelle : 0-40)

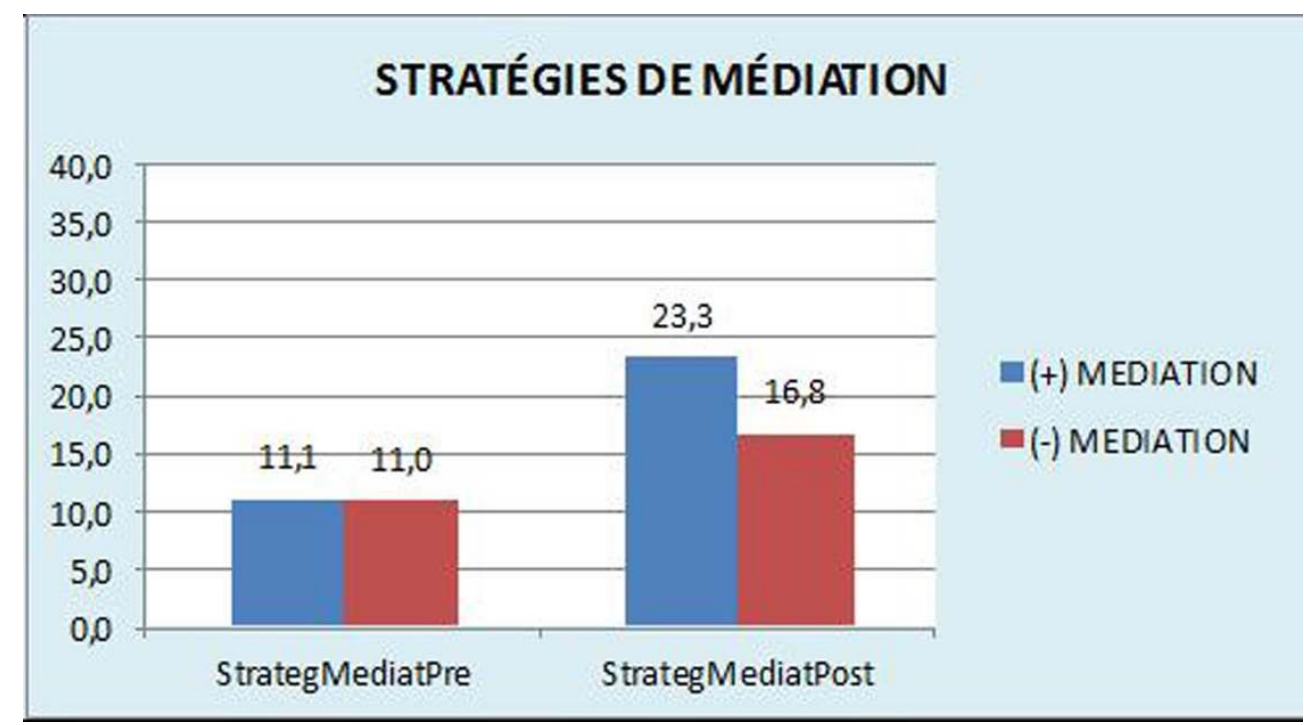

Figure 4.2 : Stratégies de médiation en langue italienne (8 items, échelle : 0-40)

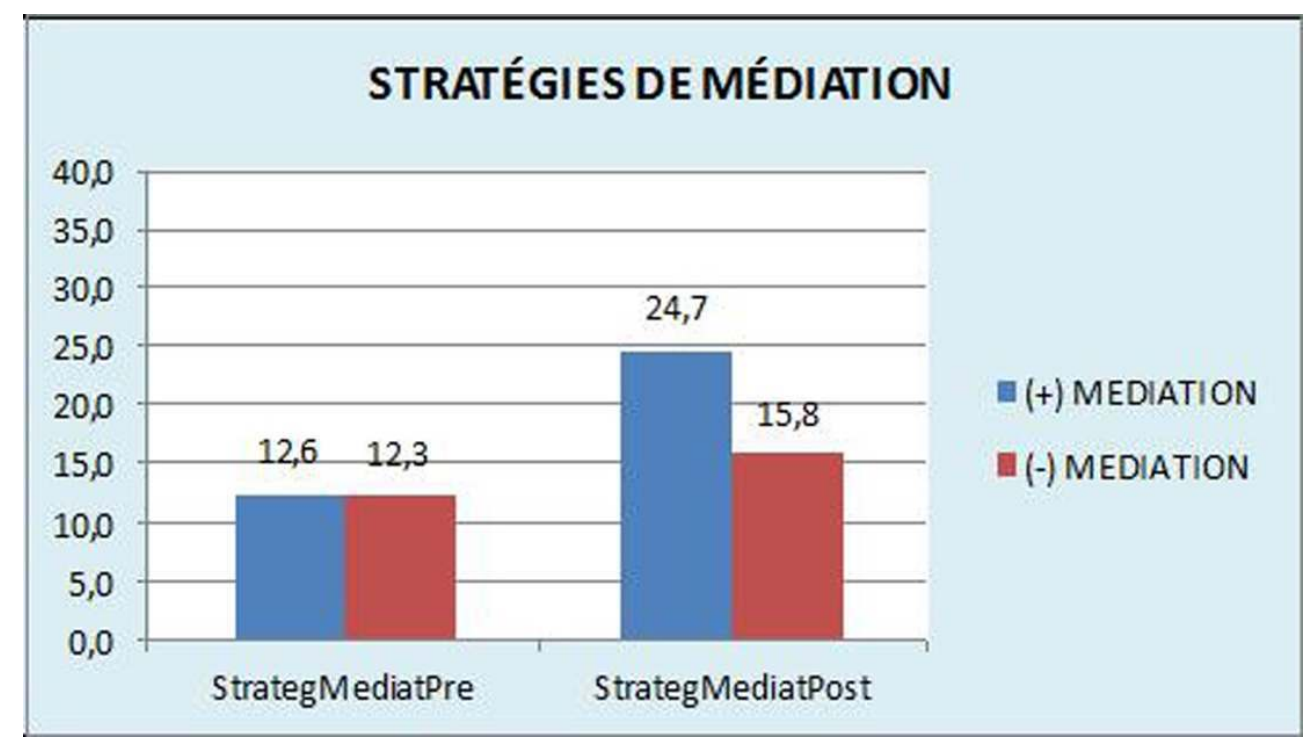

Plus concrètement, en français, nous constatons que les étudiants du groupe expérimental sont bien plus à l'aise avec ces stratégies en fin de semestre que leurs pairs du groupe témoin (avec médiation, de 11,1 à 23,3 donc une augmentation de 12,2; sans médiation, de 11,0 à 16,8 donc une hausse de 5,8). En somme, il y a une différence de 6,4 en faveur du groupe expérimental. 
51 En langue italienne, les étudiants du groupe expérimental sont également plus à l'aise avec ces stratégies en fin de semestre que leurs pairs du groupe témoin (avec médiation, de 12,6 à 24,7 donc une hausse de 12,1; sans médiation, de 12,3 à 15,8 donc une augmentation de 3,5). Au total, il y a une différence de 8,6 en faveur du groupe expérimental.

Dans le tableau 3 qui suit, sont regroupées les données d'évaluation des étudiants par les enseignants dans les deux langues étrangères avec toutes les composantes aussi bien de la médiation cognitive que des stratégies de médiation. On constate que les enseignants perçoivent une amélioration de la performance des étudiants. Les moyennes des groupes ayant suivi les cours de langue de spécialité avec médiation sont en gras.

Tableau 3 : Récapitulatif des moyennes et des différences indiquant l'amélioration en médiation (évaluation des étudiants par les enseignants)

\begin{tabular}{|c|c|c|c|c|c|c|c|}
\hline & & Langue & françai & & Langue & italien & \\
\hline & groupes & pretest & $\begin{array}{l}\text { post- } \\
\text { test }\end{array}$ & hausse & pretest & $\begin{array}{l}\text { post- } \\
\text { test }\end{array}$ & hausse \\
\hline & $\begin{array}{l}(+) \\
\text { médiation }\end{array}$ & 35,8 & 70,6 & 34,8 & 33,3 & 70,2 & 34,8 \\
\hline & $\begin{array}{l}(-) \\
\text { médiation }\end{array}$ & 32,9 & 48,8 & 15,9 & 33,6 & 46,1 & 15,9 \\
\hline & $\begin{array}{l}(+) \\
\text { médiation }\end{array}$ & 3,6 & 7,0 & 3,4 & 3,3 & 6,2 & 2,9 \\
\hline & $\begin{array}{l}(-) \\
\text { médiation }\end{array}$ & 2,9 & 4,0 & 1,1 & 2,8 & 4,0 & 1,2 \\
\hline & $\begin{array}{l}(+) \\
\text { médiation }\end{array}$ & 5,2 & 11,1 & 5,9 & 4,3 & 10,3 & 7,0 \\
\hline & $\begin{array}{l}(-) \\
\text { médiation }\end{array}$ & 4,8 & 7,8 & 3,0 & 4,2 & 7,2 & 4,0 \\
\hline expliquer des données à l'oral & $\begin{array}{l}(+) \\
\text { médiation }\end{array}$ & 3,7 & 6,4 & 2,7 & 2,5 & 6,6 & 4,1 \\
\hline (graphiques, diagrammes, etc.) & $\begin{array}{l}(-) \\
\text { médiation }\end{array}$ & 3,4 & 4,6 & 1,2 & 3,1 & 4,6 & 1,5 \\
\hline & $\begin{array}{l}(+) \\
\text { médiation }\end{array}$ & 10,6 & 19,4 & 8,8 & 9,2 & 19,6 & 10,4 \\
\hline & $\begin{array}{l}(-) \\
\text { médiation }\end{array}$ & 9,3 & 13,7 & 4,4 & 9,9 & 12,8 & 2,9 \\
\hline traduire à l'oral un texte écrit & $\begin{array}{l}(+) \\
\text { médiation }\end{array}$ & 1,7 & 3,2 & 1,5 & 1,4 & 2,8 & 1,4 \\
\hline
\end{tabular}

(traduction à vue) 


\begin{tabular}{|c|c|c|c|c|c|c|c|}
\hline & $\begin{array}{l}(-) \\
\text { médiation }\end{array}$ & 1,4 & 2,0 & 0,6 & 1,3 & 1,7 & 0,4 \\
\hline \multirow{2}{*}{ Stratégies de médiation } & $\begin{array}{l}(+) \\
\text { médiation }\end{array}$ & 11,1 & 23,3 & 12,2 & 12,6 & 24,7 & 12,1 \\
\hline & $\begin{array}{l}(-) \\
\text { médiation }\end{array}$ & 11,0 & 16,8 & 5,8 & 12,3 & 15,8 & 3,5 \\
\hline \multirow{2}{*}{ relier à un savoir préalable } & $\begin{array}{l}(+) \\
\text { médiation }\end{array}$ & 1,2 & 3,0 & 1,8 & 2,1 & 3,3 & 1,2 \\
\hline & $\begin{array}{l}(-) \\
\text { médiation }\end{array}$ & 1,1 & 2,0 & 0,4 & 1,5 & 2,1 & 0,6 \\
\hline \multirow{2}{*}{ développer un texte } & $\begin{array}{l}(+) \\
\text { médiation }\end{array}$ & 4,4 & 8,1 & 3,7 & 4,6 & 9,2 & 4,6 \\
\hline & $\begin{array}{l}(-) \\
\text { médiation }\end{array}$ & 4,3 & 6,4 & 2,1 & 4,7 & 6,1 & 1,4 \\
\hline \multirow{2}{*}{ rationaliser un texte } & $\begin{array}{l}(+) \\
\text { médiation }\end{array}$ & 2,8 & 6,4 & 3,6 & 3,2 & 6,4 & 3,2 \\
\hline & $\begin{array}{l}(-) \\
\text { médiation }\end{array}$ & 2,9 & 4,3 & 1,4 & 3,1 & 4,0 & 0,9 \\
\hline \multirow{2}{*}{$\begin{array}{l}\text { décomposer une information } \\
\text { complexe }\end{array}$} & $\begin{array}{l}(+) \\
\text { médiation }\end{array}$ & 1,2 & 2,8 & 1,6 & 1,4 & 3,1 & 1,7 \\
\hline & $\begin{array}{l}(-) \\
\text { médiation }\end{array}$ & 1,3 & 2,0 & 0,7 & 1,5 & 1,9 & 0,4 \\
\hline \multirow{2}{*}{ adapter son langage } & $\begin{array}{l}(+) \\
\text { médiation }\end{array}$ & 1,4 & 3,0 & 1,6 & 1,3 & 2,7 & 1,4 \\
\hline & $\begin{array}{l}(-) \\
\text { médiation }\end{array}$ & 1,3 & 2,0 & 0,7 & 1,5 & 1,7 & 0,2 \\
\hline
\end{tabular}

souhaiterions mentionner, à titre indicatif, les résultats concernant deux composantes de la médiation cognitive. En matière de transmission d'informations spécifiques à l'oral (Qs: B1, B2, B3), nous constatons une nette amélioration avec une différence des moyennes de l'ordre de 5,9 pour le groupe expérimental de français et une différence également importante de l'ordre de 7,0 pour l'italien.

En outre, pour ce qui du traitement d'un texte à l'oral (Qs : D1, D2, D3, D4, D5, D6), le groupe expérimental de français l'emporte sur le groupe témoin avec une différence de moyennes de 8,8 et pour l'italien un écart de 10,4.

Il en est de même pour les stratégies de médiation. En matière de développement de texte (Qs : G1, G2, G3), nous observons une différence des moyennes de l'ordre de 3,7 pour le groupe expérimental de français et une différence plus importante de l'ordre de 4,6 pour 
l'italien, donc une nette amélioration. De plus, pour ce qui est de la rationalisation d'un texte (Qs : H1, H2), les différences sont de 3,6 pour le groupe expérimental en français et de 3,2 pour le groupe expérimental en italien.

\subsubsection{Création d'un glossaire trilingue spécialisé et réponses à des questions associées}

Les figures 5.1.1 et 5.1.2 représentent les graphiques qui regroupent les moyennes des performances des étudiants en français et en italien quant à la recherche d'équivalents au moyen de la reconnaissance d'une langue romane en début et en fin de semestre avec et sans médiation ainsi que l'autoévaluation des performances des étudiants construisant le glossaire trilingue.

Figure 5.1.1 : Glossaire trilingue spécialisé au prétest et au post-test en langue française (moyenne des réponses aux quatre exercices du glossaire; notation de 0 à 10)

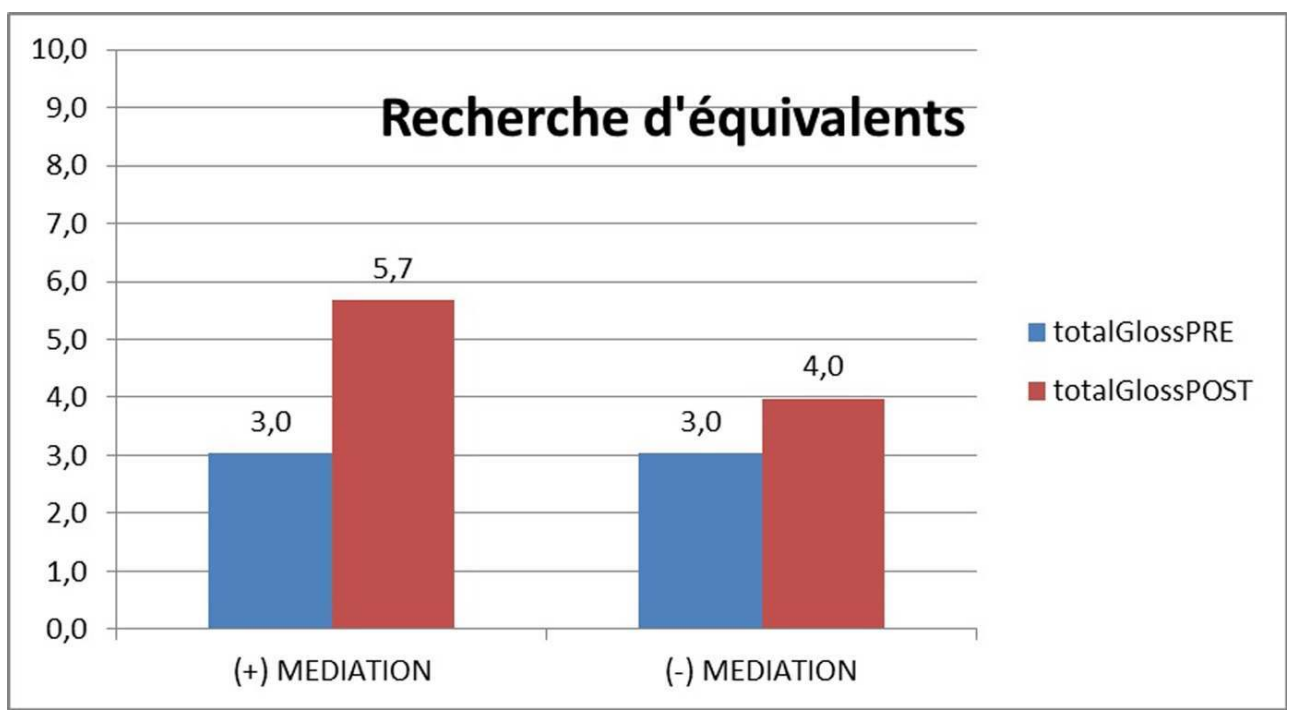

Figure 5.1.2: Glossaire trilingue spécialisé au prétest et au post-test en langue italienne (moyenne des réponses aux quatre exercices du glossaire; notation de 0 à 10)

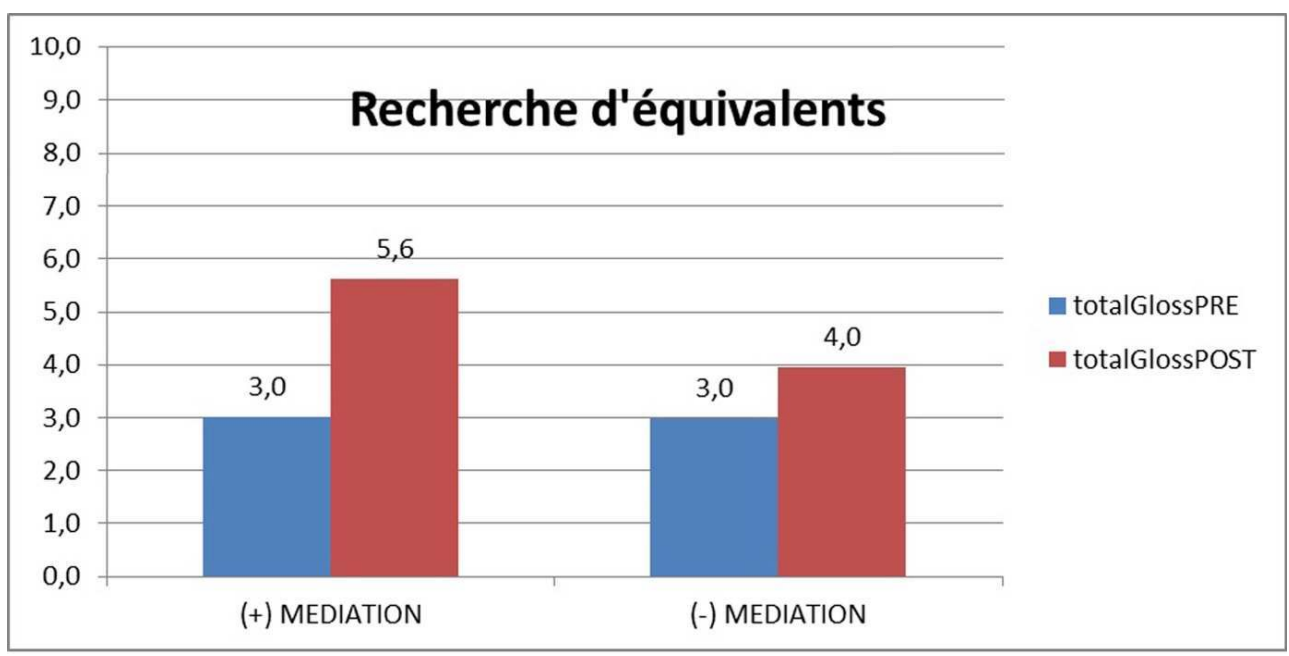

Malgré le point de départ commun $(3,0)$ pour les deux groupes en français, on constate une amélioration beaucoup plus importante $(5,7)$ pour le groupe expérimental que pour 
le groupe témoin $(4,0)$, donc une différence des moyennes de 2,7 pour l'un et de 1,0 pour l'autre. La situation est plus ou moins identique pour l'italien.

Quant aux questions formulées dans le questionnaire concernant le glossaire trilingue (voir annexes 2.1,2.2), les réponses des étudiants (figures 5.2.1 et 5.2.2) corroborent notre constatation sur la performance améliorée en français et en italien des groupes expérimentaux grâce d'une part à la médiation lors du cours, d'autre part à la ressemblance des termes français recherchés avec les termes italiens qui servaient d'indices.

Figure 5.2.1 : Autoévaluation glossaire trilingue en langue française (3 items, échelle: -9 - +9)

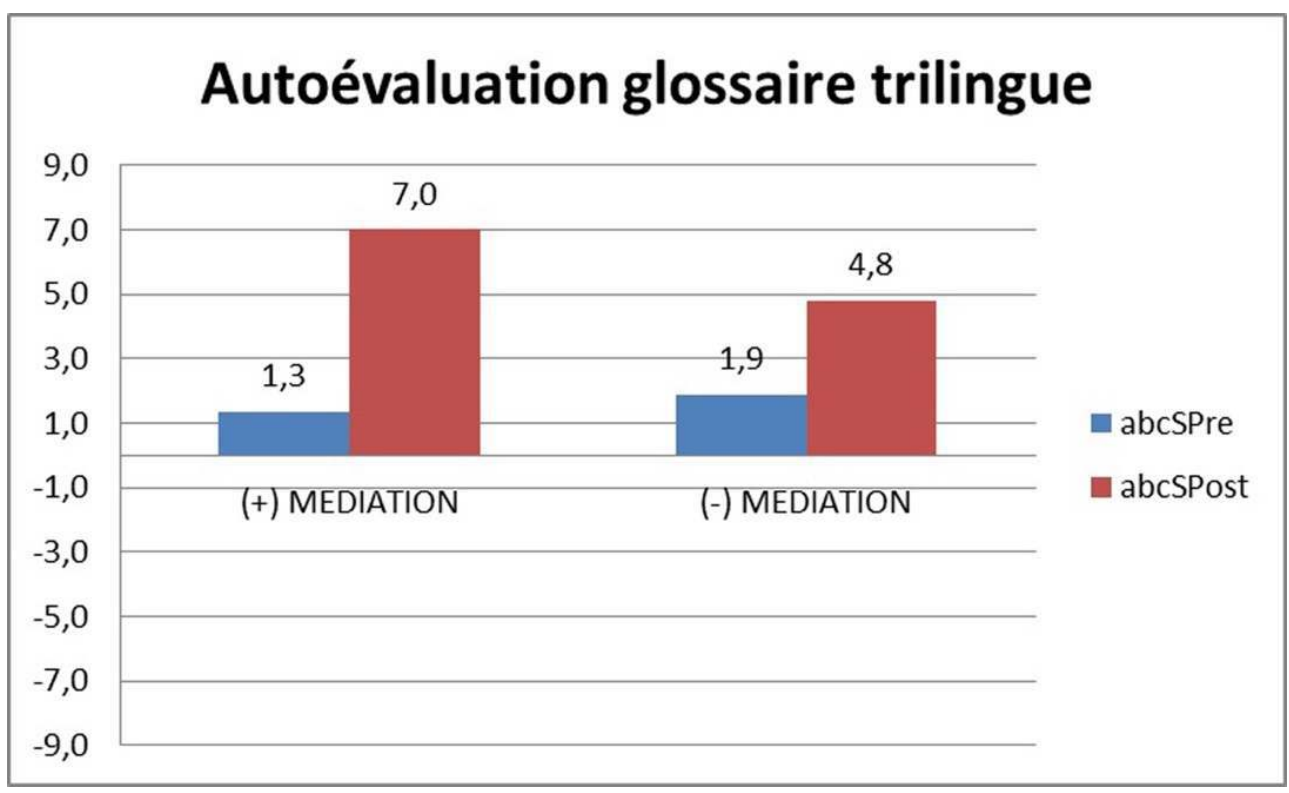

Figure 5.2.2 : Autoévaluation glossaire trilingue en langue italienne (3 items, échelle: -9 - +9)

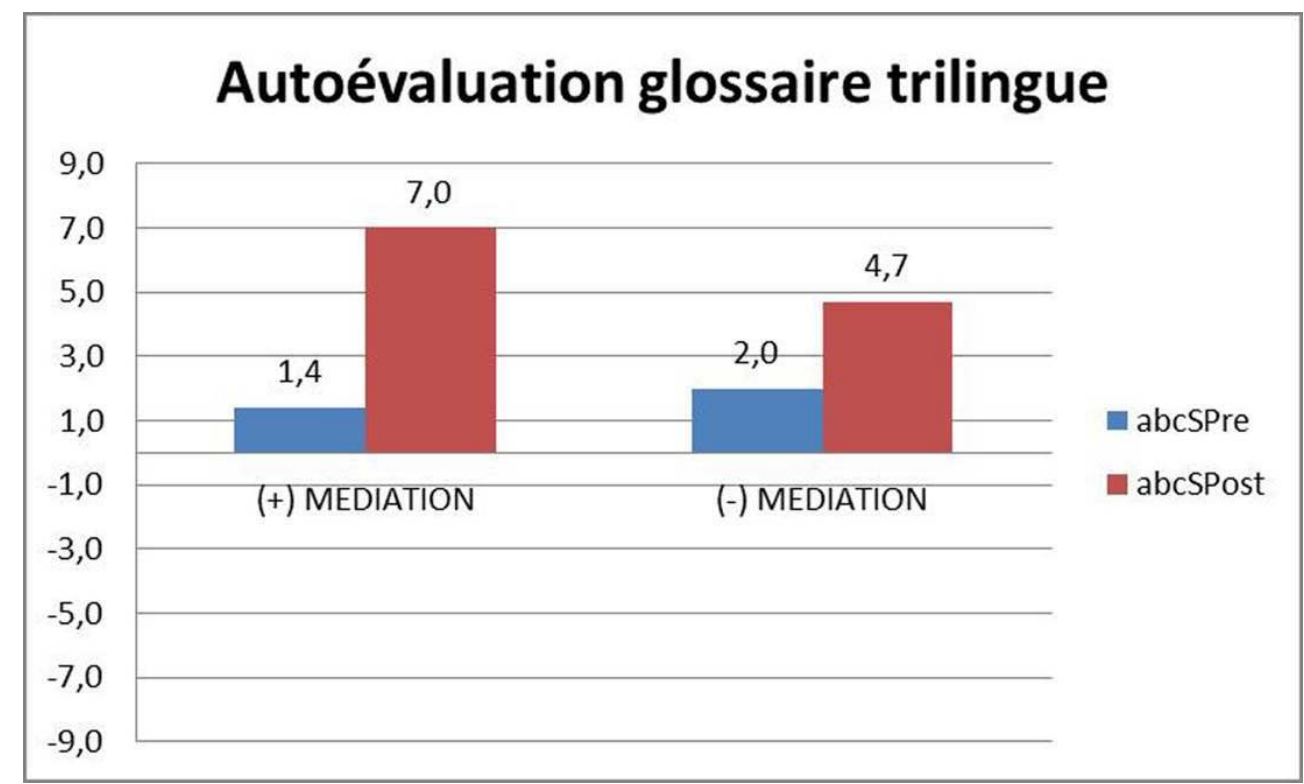

Par ailleurs, la figure 6 présente un extrait du glossaire trilingue spécialisé en ligne établi de façon collaborative au long du semestre. 
Figure 6 : Glossaire trilingue spécialisé sur un document partagé en ligne

\begin{tabular}{|c|c|c|c|c|}
\hline FRANCCAIS & $\nabla$ & EMAHNIKA & D & ITALIANO \\
\hline produit national brut (un) & & акаӨव́рібто єӨทкó проїóv & & prodotto nazionale lordo (un) \\
\hline droit commercial (un) & & 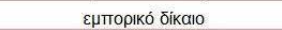 & & diritto commerciale (un) \\
\hline biens (des) & & aүa $\theta \dot{a}$ & & beni (dei) \\
\hline juridiction (une) & & 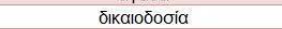 & & giurisdizione (una) \\
\hline licence (une) & & áర̄દાa & & licenza (una) \\
\hline permis de travail (un) & & 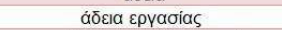 & & permesso di lavoro (un) \\
\hline produit intérieur brut (un) & & 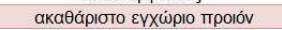 & & prodotto interno lordo (un) \\
\hline valeur réelle (une) & & 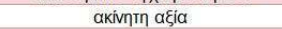 & & valore reale (un) \\
\hline rémunération (une) & & aнoißń & & retribuzione (una) \\
\hline négociation interprofessionnelle (une) & & 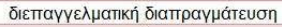 & & negoziazione interprofessionale (una) \\
\hline reconduction (une) & & avavéwơn & & rinnovo (un) \\
\hline à but lucratif & & 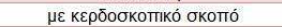 & & a scopo di lucro \\
\hline représentant (un) & & 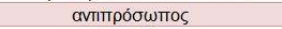 & & rappresentante (un) \\
\hline compensation (une) & & 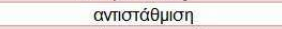 & & compensazione (una) \\
\hline société anonyme (une) & & 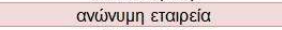 & & società anonima (una) \\
\hline démission (une) & & mapaimnon & & dimissione (una) \\
\hline grève (une) & & aाгруía & & sciopero (uno) \\
\hline prélèvement (un) & & 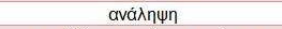 & & prelievo (un) \\
\hline contrat à durée indéterminée (un) & & 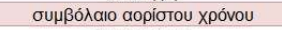 & & contratto a tempo indeterminato (un) \\
\hline indemniser & & 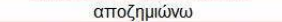 & & indennizzare \\
\hline
\end{tabular}

Outre la médiation, ses stratégies et le glossaire, nous nous intéressons aussi à la traduction français-grec et italien-grec en tant que modules à part.

\subsubsection{Résultats des questionnaires des étudiants en traduction}

Les graphiques des figures 7.1 et 7.2 représentent la compréhension de texte telle qu'elle résulte de l'autoévaluation des étudiants au prétest et au post-test en cours de traduction.

Figure 7.1 : Compréhension du texte original en vue d'une traduction français-grec et italien-grec en langue française (correspond aux questions 1, 2, 4, 5 du questionnaire-annexe 3 ; la moyenne varie de 0 à 5 )

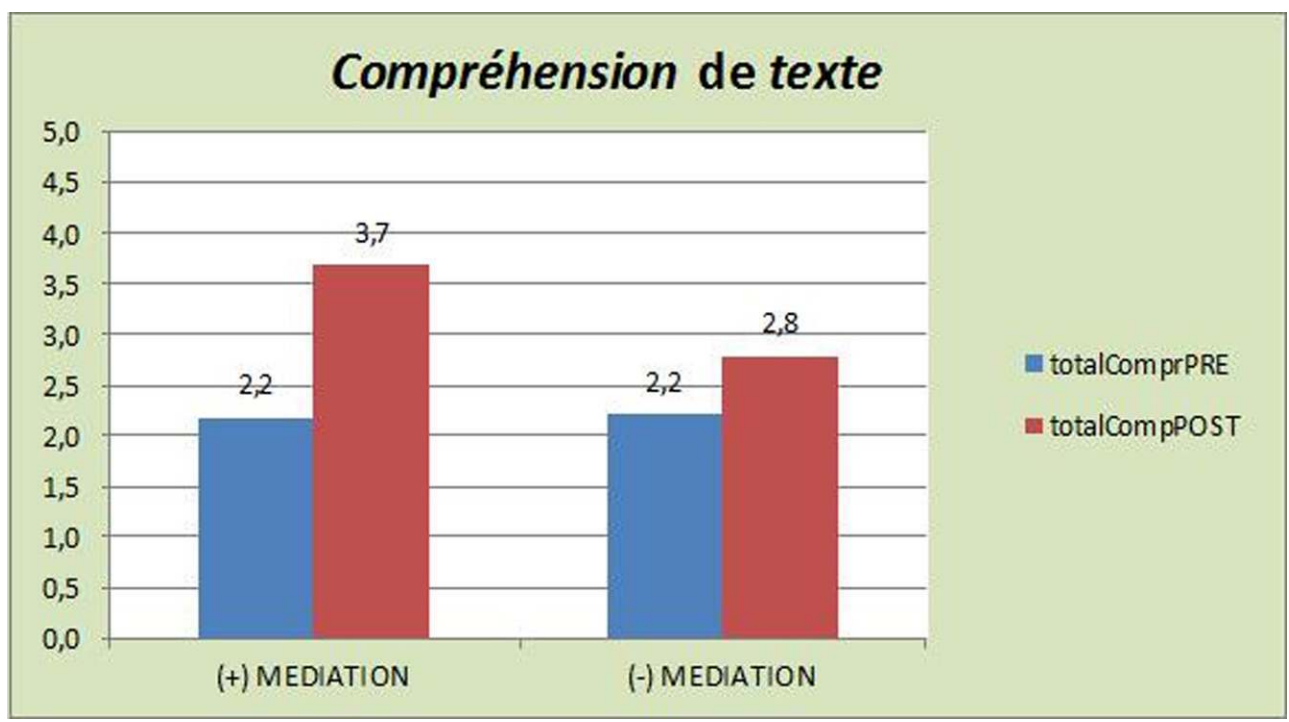


Figure 7.2: Compréhension du texte original en vue d'une traduction français-grec et italien-grec en langue italienne (correspond aux questions 1, 2, 4, 5 du questionnaire-annexe 3 ; la moyenne varie de 0 à 5 )

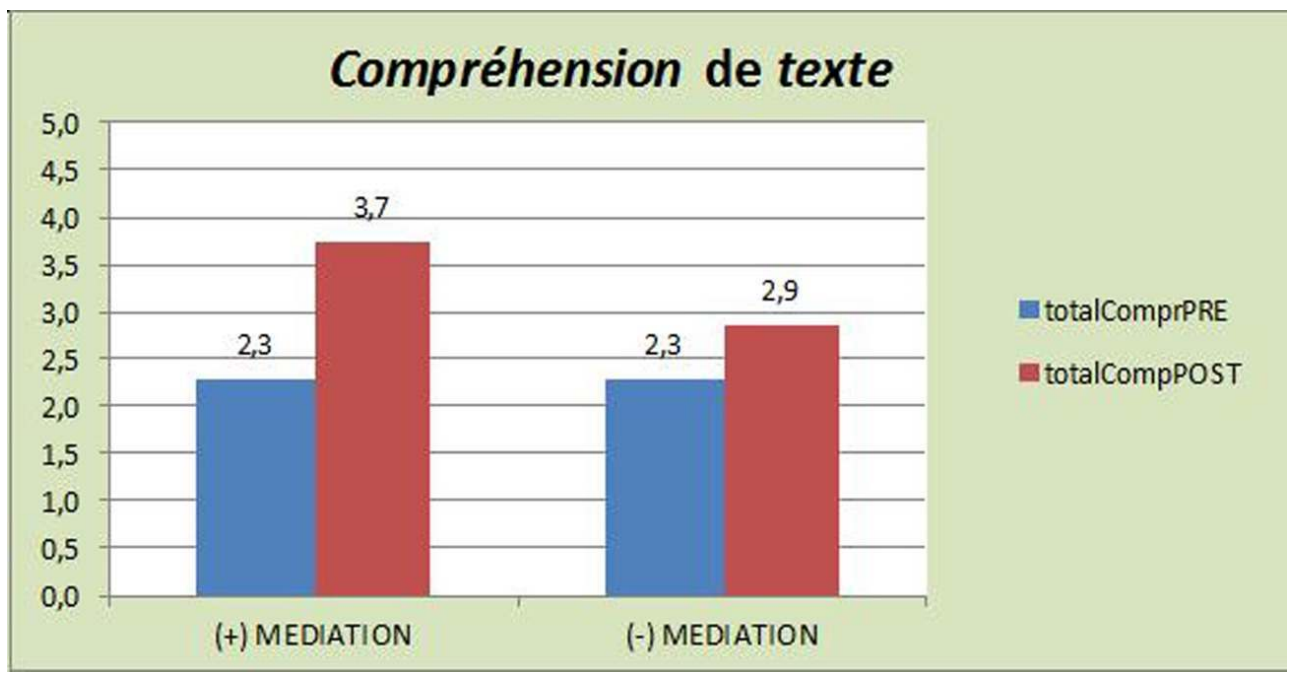

62 Alors que les deux groupes de français ont eu 2,2 comme point de départ commun, en fin de semestre la compréhension de texte pour le groupe expérimental s'élève à 3,7 contre 2,8 pour le groupe témoin, donc une différence de 0,9 . En traduction italien-grec, le point de départ de 2,3 a été commun pour les deux groupes alors qu'en fin de semestre nous avons observé une différence de 0,8 (3,7 contre 2,9$)$ en faveur du groupe expérimental.

Les graphiques des figures 8.1 et 8.2 montrent la compétence d'extraction de termes en traduction français-grec et italien-grec. Il n'y a pas d'échelle bien précise car les deux graphiques représentent les moyennes des totaux des termes repérés selon les réponses aux questions 3.1, 3.2, 3.3 du questionnaire d'autoévaluation des étudiants en traduction spécialisée (annexe 3).

Figure 8.1 : Compétence d'extraction de termes en traduction français-grec

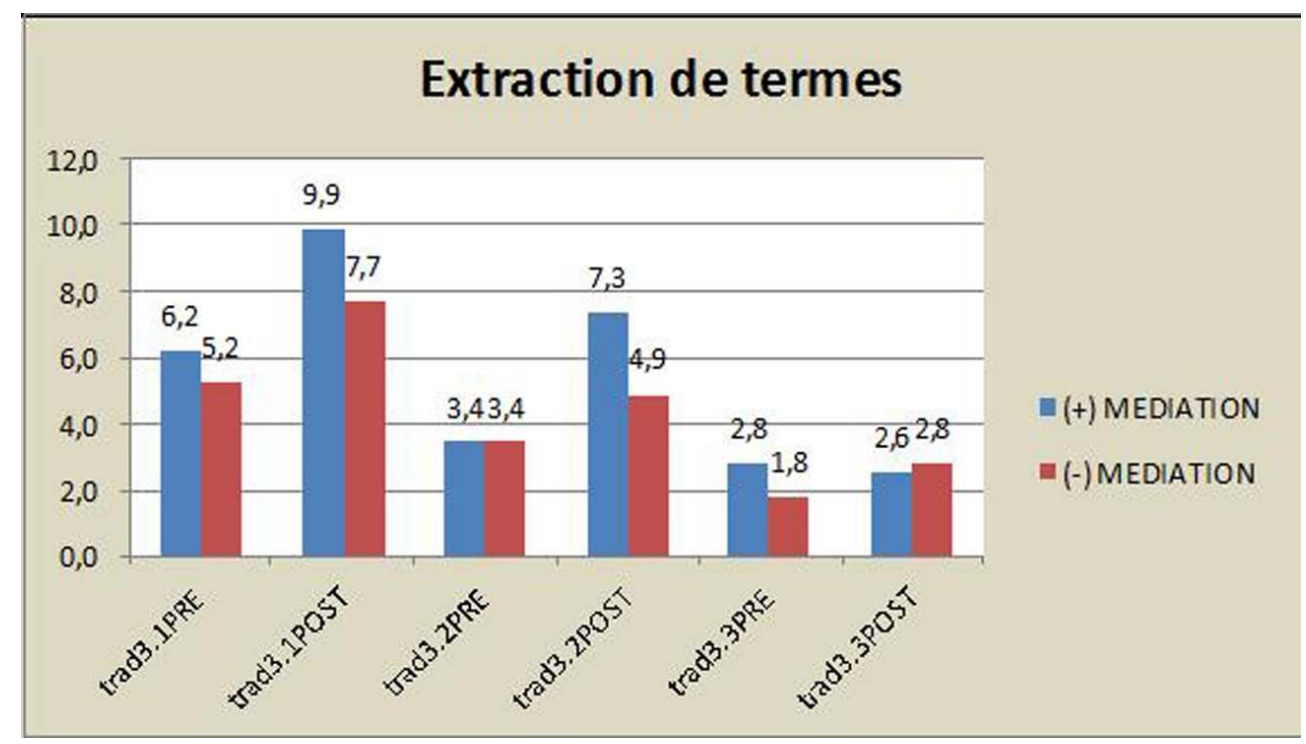




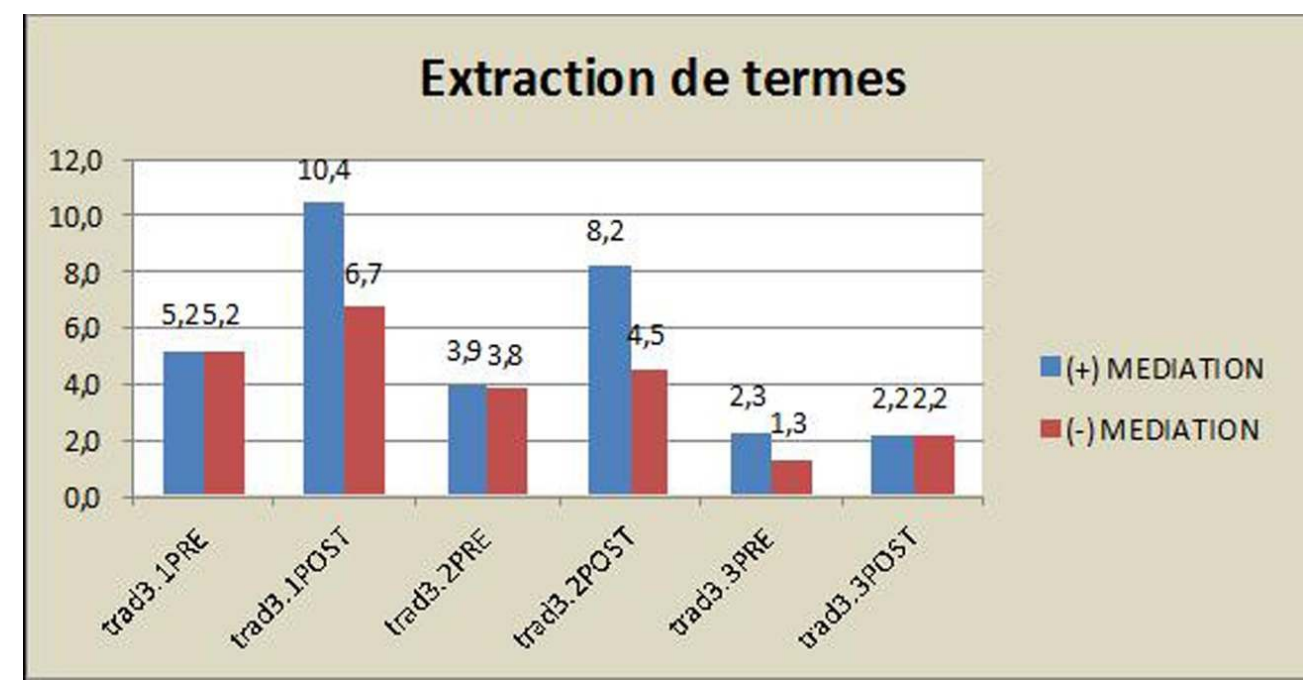

En ce qui concerne le repérage de termes en français, la différence de 1,0 entre les deux groupes en début de semestre augmente à 2,2 lors du post-test. Plus particulièrement, en début de semestre les deux groupes sont à égalité quant à leur certitude d'avoir rencontré des termes connus tandis qu'à la fin le groupe expérimental l'emporte avec 7,3 contre 4,9 du groupe témoin, donc une différence de 2,4. Enfin, pour ce qui est des termes inconnus, malgré la distance initiale en faveur du groupe témoin dont les membres avaient moins de termes inconnus, le groupe expérimental finit par prendre le pas avec une petite différence de 0,2 .

Quant au repérage de termes en italien, l'égalité entre les deux groupes au début donne sa place à 3,7 de différence lors du post-test. Plus particulièrement, les deux groupes au départ sont presque à égalité quant à leur certitude d'avoir rencontré des termes connus alors qu'à la fin nous constatons que le groupe expérimental fait preuve d'une nette amélioration avec 8,2 contre 4,5 du groupe témoin, donc le groupe expérimental avance de 3,7. Enfin, en matière de termes inconnus, malgré la différence initiale de 1,0 en faveur du groupe témoin dont les étudiants avaient moins de termes inconnus, les deux groupes finissent par obtenir le même score.

Les tableaux des figures 9.1 et 9.2 mettent en évidence la consultation accrue de textes comparables ou parallèles de la part des étudiants du groupe expérimental par rapport à ceux du groupe témoin. 
Figure 9.1 : Recours des étudiants à des textes comparables ou parallèles en traduction françaisgrec (question 6 de l'annexe 3 ; échelle 0-5)

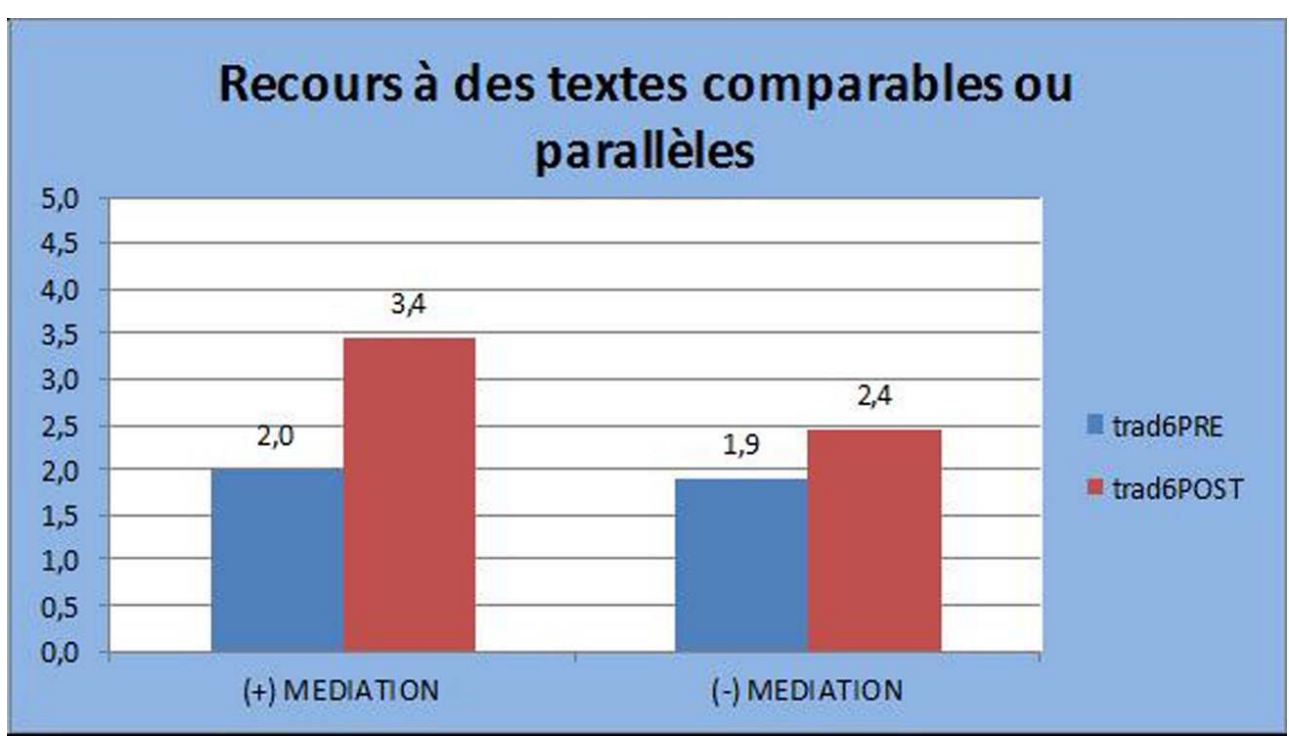

Figure 9.2: Recours des étudiants à des textes comparables ou parallèles en traduction italien-grec (question 6 de l'annexe 3 ; échelle 0-5)

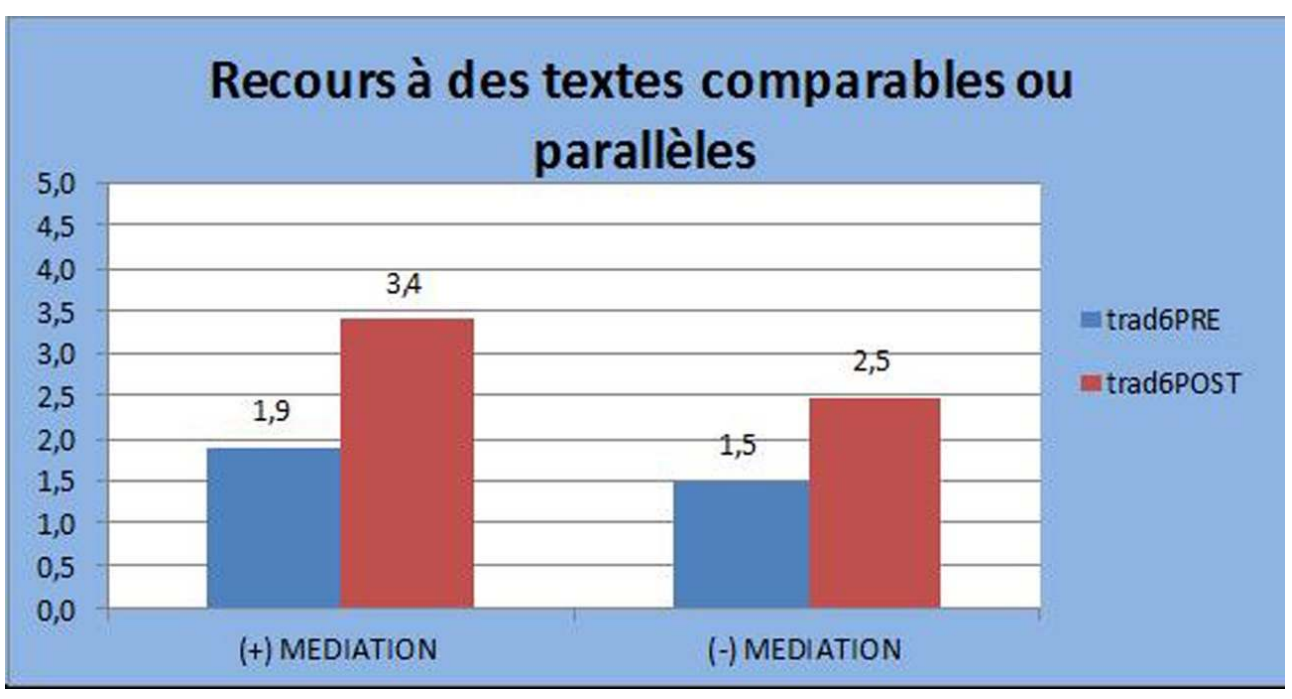

67 Malgré un départ presque aussi dynamique pour les deux groupes dans les deux langues, la différence s'élève à 0,9 et à 0,5 pour les groupes expérimentaux respectivement en français et en italien en fin de semestre.

Les tableaux des figures 10.1 et 10.2 présentent l'autoévaluation de la compréhension globale de texte. 
Figure 10.1 : Autoévaluation en compréhension globale de texte en français (question 7 de l'annexe 3 ; échelle 0-5)

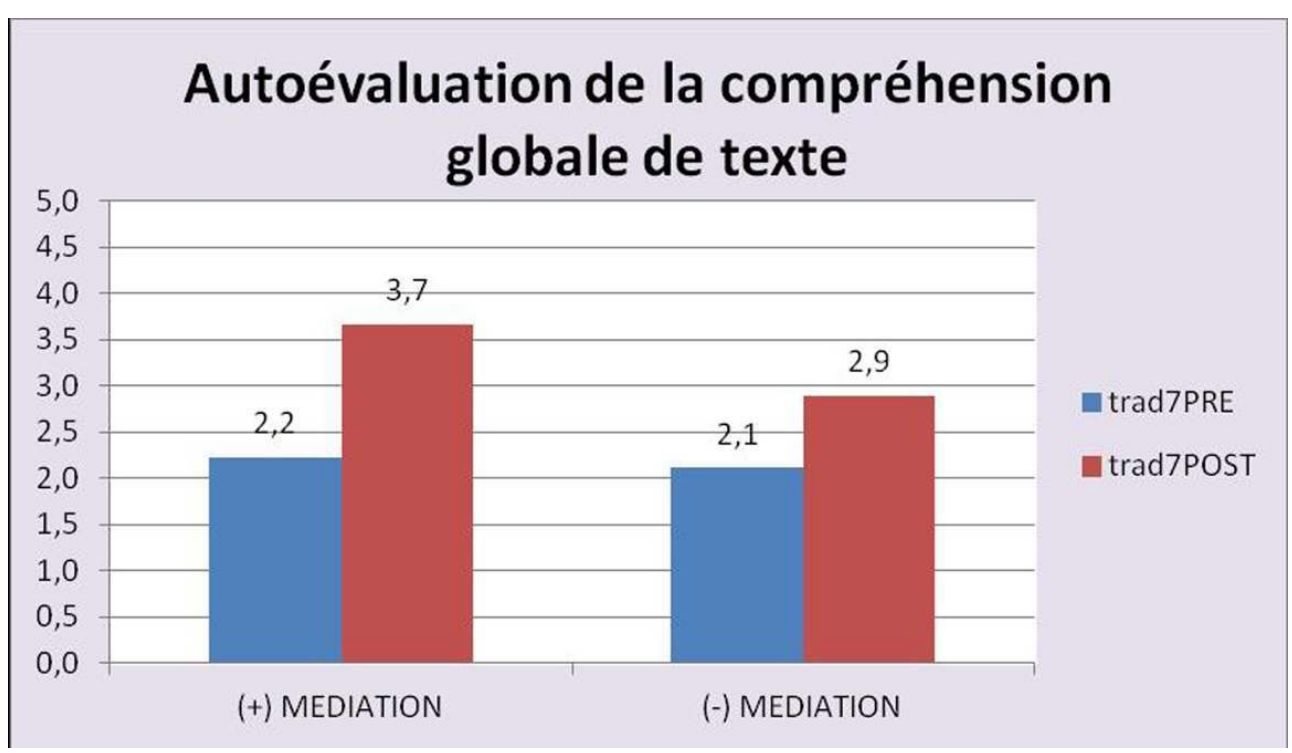

Figure 10.2: Autoévaluation en compréhension globale de texte en italien (question 7 de l'annexe 3 ; échelle 0-5)

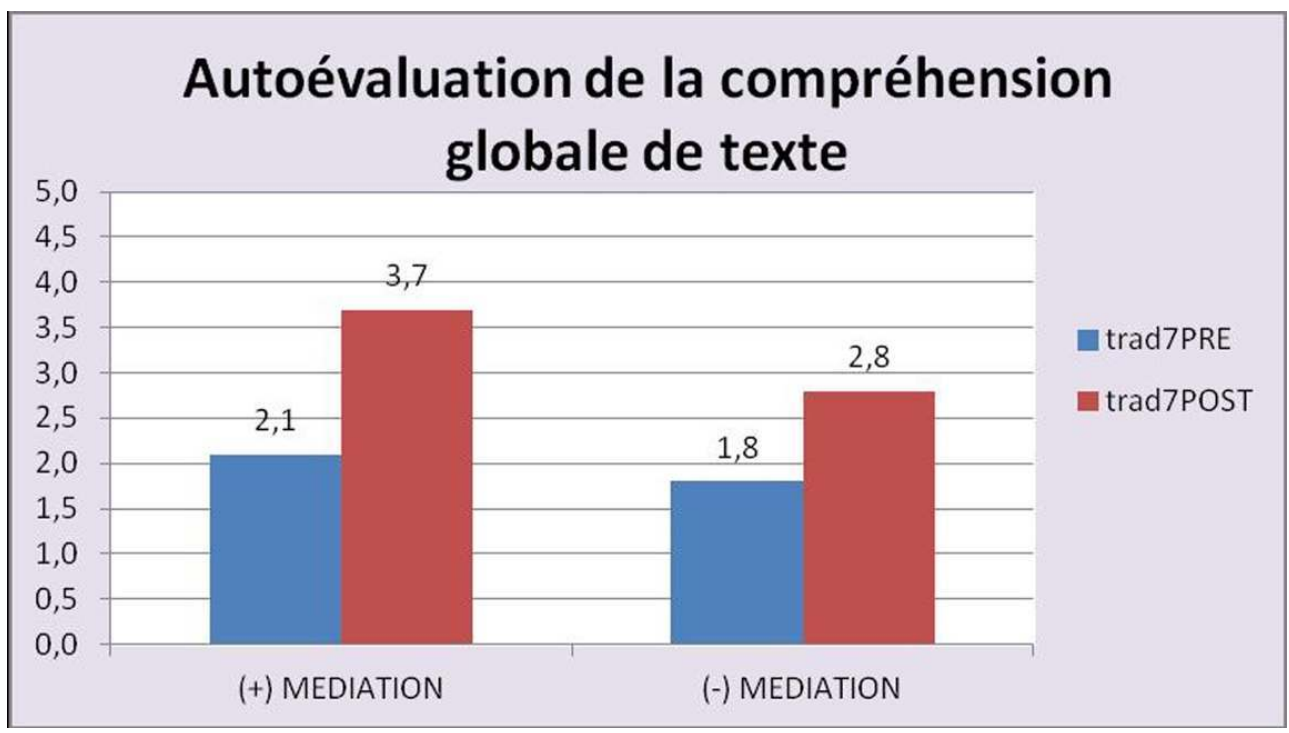

On constate qu'en fin de semestre, malgré un niveau de départ presque égal entre les deux groupes de traduction, le groupe expérimental fait preuve d'une compréhension bien meilleure que celle du groupe témoin avec une différence de 0,7 pour le français et de 0,6 pour l'italien.

2.1.5 Evaluation de la performance des étudiants en traduction français-grec et italien-grec par les enseignants

Les tableaux des figures 11.1 et 11.2 présentent l'évaluation sommative de la traduction français-grec et italien-grec. 
Figure 11.1 : Évaluation sommative de la traduction français-grec (notation de traduction ; échelle 0-10)

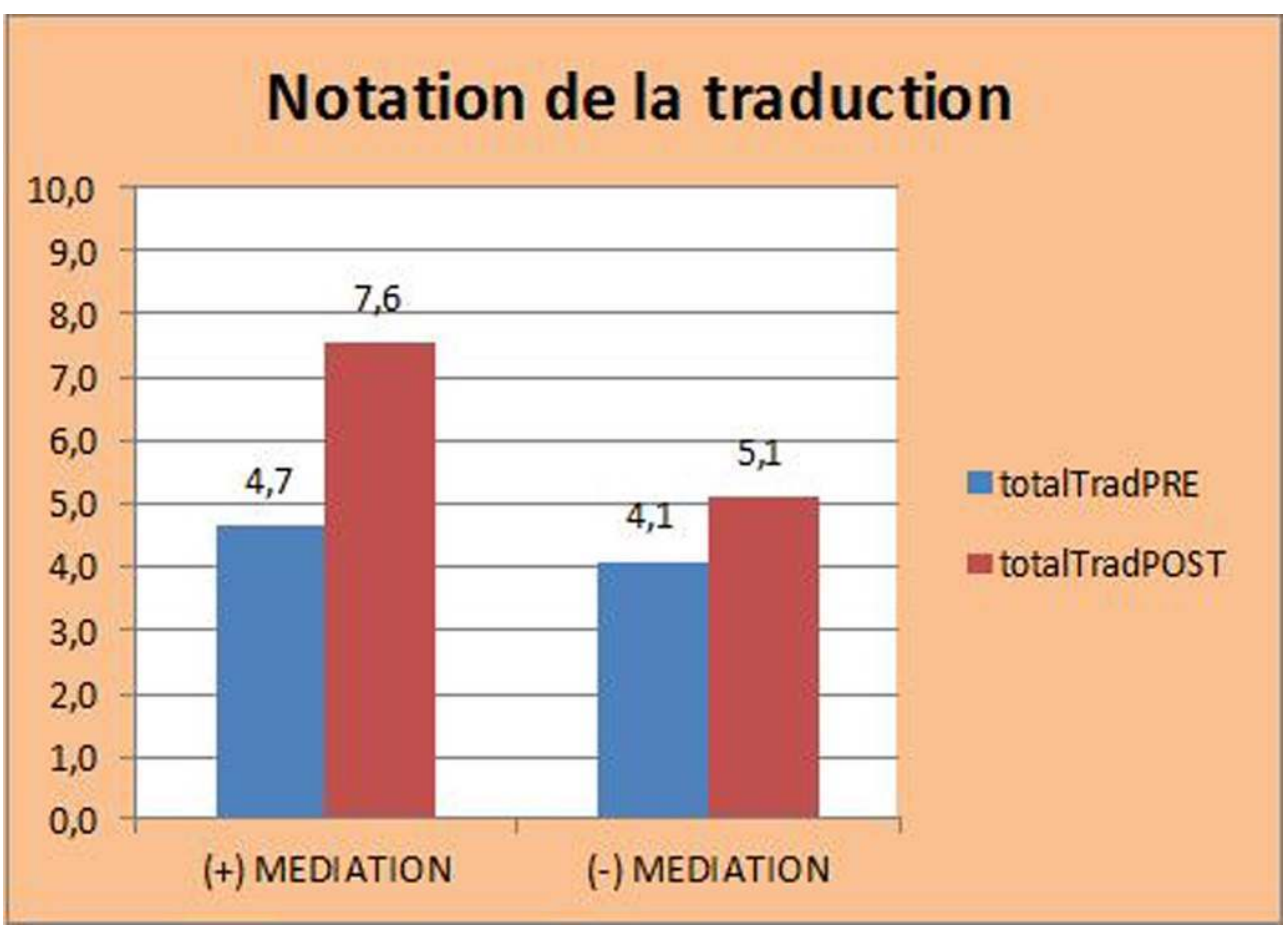

Figure 11.2 : Évaluation sommative de la traduction italien-grec (notation de traduction ; échelle 0-10)

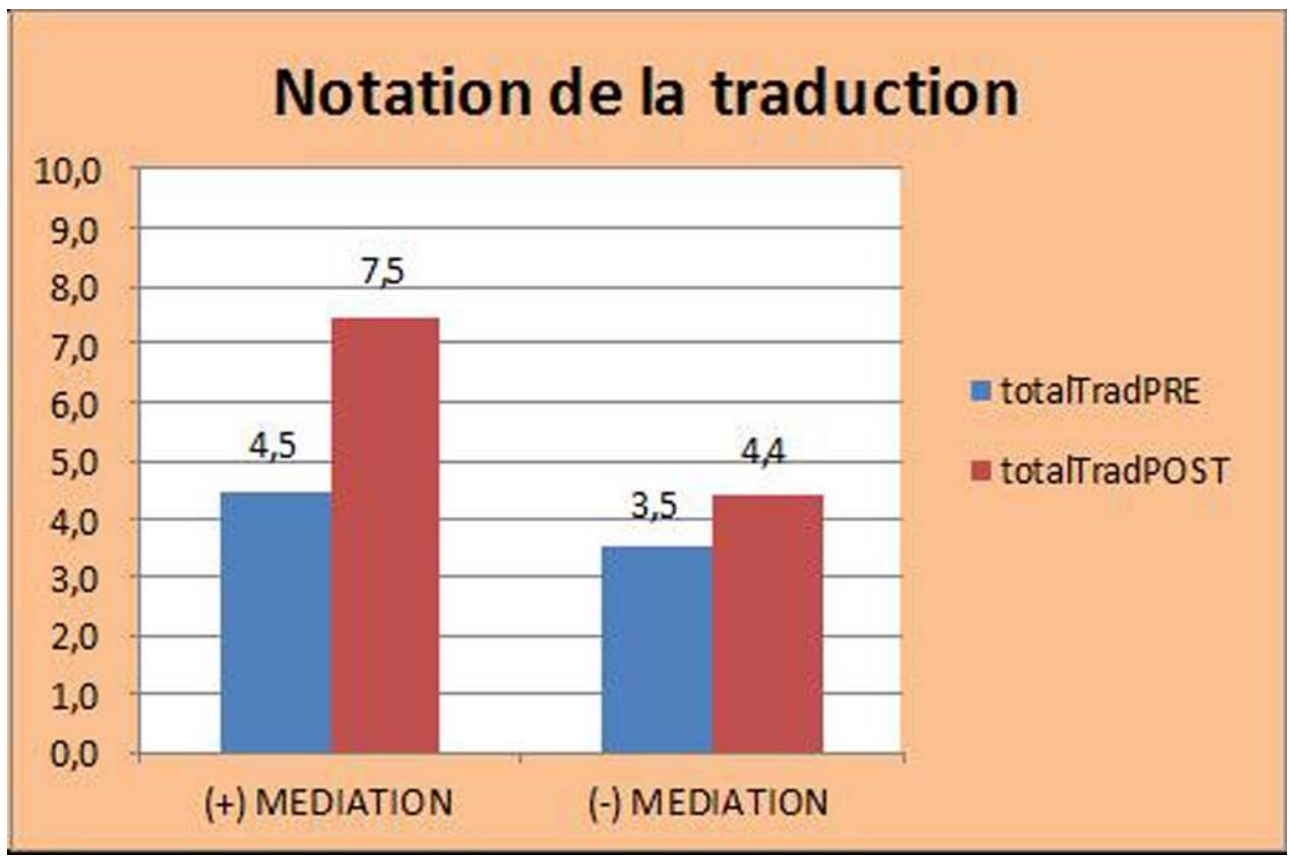

Du côté des enseignants, les copies des étudiants en fin de semestre montrent une amélioration de 2,9 pour la traduction français-grec et de 3,0 pour la traduction italiengrec quant à la qualité de traduction des étudiants du groupe expérimental contre une hausse de performance d'à peine 1,0 pour ceux du groupe témoin. 
Le tableau 4 montre d'une part l'autoévaluation des étudiants et d'autre part l'évaluation sommative de la traduction par les enseignants. Il regroupe les moyennes de la performance des étudiants au prétest et au post-test en cours de traduction spécialisée ainsi que l'amélioration de performance entre le début et la fin du semestre pour les deux langues. Les moyennes des groupes ayant suivi les cours de langue avec médiation sont en gras. On constate que les groupes qui avaient suivi le cours de langue avec médiation ont eu un meilleur score en traduction spécialisée.

Tableau 4 : Récapitulatif des cours de traduction (autoévaluation des étudiants et évaluation par les enseignants)

\begin{tabular}{|c|c|c|c|c|c|c|c|}
\hline \multirow{2}{*}{\begin{tabular}{|l} 
Autoévaluation des étudiants \\
\end{tabular}} & \multirow[b]{2}{*}{ groups } & \multicolumn{3}{|c|}{$\begin{array}{l}\text { Traduction français - } \\
\text { grec }\end{array}$} & \multicolumn{3}{|c|}{$\begin{array}{l}\text { Traduction italien - } \\
\text { grec }\end{array}$} \\
\hline & & pretest & $\begin{array}{l}\text { post- } \\
\text { test }\end{array}$ & hausse & prétest & $\begin{array}{l}\text { post- } \\
\text { test }\end{array}$ & hausse \\
\hline \multirow{2}{*}{ Compréhension de texte } & $\begin{array}{l}(+) \\
\text { médiation }\end{array}$ & 2,2 & 3,7 & 1,5 & 2,3 & 3,7 & 1,4 \\
\hline & $\begin{array}{l}(-) \\
\text { médiation }\end{array}$ & 2,2 & 2,8 & 0,6 & 2,3 & 2,9 & 0,6 \\
\hline \multirow{2}{*}{ Extraction de termes (totalité) } & $\begin{array}{l}(+) \\
\text { médiation }\end{array}$ & 6,2 & 9,9 & 3,7 & 5,2 & 10,4 & 5,2 \\
\hline & $\begin{array}{l}(-) \\
\text { médiation }\end{array}$ & 5,2 & 7,7 & 2,5 & 5,2 & 6,7 & 1,5 \\
\hline \multirow{2}{*}{$\begin{array}{l}\text { Extraction de termes (termes } \\
\text { connus) }\end{array}$} & $\begin{array}{l}(+) \\
\text { médiation }\end{array}$ & 3,4 & 7,3 & 3,9 & 3,9 & 8,2 & 4,3 \\
\hline & $\begin{array}{l}(-) \\
\text { médiation }\end{array}$ & 3,4 & 4,9 & 1,5 & 3,8 & 4,5 & 0,7 \\
\hline \multirow{2}{*}{$\begin{array}{l}\text { Extraction de termes (termes } \\
\text { inconnus) }\end{array}$} & $\begin{array}{l}(+) \\
\text { médiation }\end{array}$ & 2,8 & 2,6 & $-0,2$ & 2,3 & 2,2 & $-0,1$ \\
\hline & $\begin{array}{l}(-) \\
\text { médiation }\end{array}$ & 1,8 & 2,8 & 1,0 & 1,3 & 2,2 & 0,9 \\
\hline \multirow{2}{*}{$\begin{array}{l}\text { Recours à des textes } \\
\text { comparables ou parallèles }\end{array}$} & $\begin{array}{l}(+) \\
\text { médiation }\end{array}$ & 2,0 & 3,4 & 1,4 & 1,9 & 3,4 & 1,5 \\
\hline & $\begin{array}{l}(-) \\
\text { médiation }\end{array}$ & 1,9 & 2,4 & 0,5 & 1,5 & 2,5 & 1,0 \\
\hline \multirow{2}{*}{$\begin{array}{l}\text { Autoévaluation de la } \\
\text { compréhension globale de texte }\end{array}$} & $\begin{array}{l}(+) \\
\text { médiation }\end{array}$ & 2,2 & 3,7 & 1,5 & 2,1 & 3,7 & 1,6 \\
\hline & $\begin{array}{l}(-) \\
\text { médiation }\end{array}$ & 2,1 & 2,9 & 0,8 & 1,8 & 2,8 & 1,0 \\
\hline
\end{tabular}




\begin{tabular}{|l|l|l|l|l|l|l|l|}
\hline \multirow{2}{*}{ Notation de la traduction par les enseignants } & $(+)$ médiation & 4,7 & 7,6 & 5,1 & 4,5 & 7,5 & $\mathbf{3 , 0}$ \\
\cline { 2 - 7 } & $(-)$ médiation & 4,1 & 5,1 & 1,0 & 3,5 & 4,4 & 0,9 \\
\hline
\end{tabular}

\subsection{Comparaison des moyennes par le biais du test-t}

Nous avons comparé les moyennes correspondant aux paramètres étudiés par le biais du test-t. Notons que le test-t est un test paramétrique reposant sur des comparaisons de moyennes quand il faut savoir si la différence entre moyennes de deux échantillons indépendants, dans notre cas le groupe expérimental et le groupe témoin, est statistiquement significative (Field [2009:285-288]). Cette série de tests nous a montré que la différence des moyennes respectives est négligeable pour les deux groupes pour les deux langues en début de semestre, ce qui n'est pas le cas en fin de semestre du fait que selon le test-t les chiffres tendent vers ou atteignent zéro (en gras dans les tableaux qui suivent).

À titre indicatif, le tableau 5 illustre la différence des moyennes statistiquement non significative au début du semestre qui devient statistiquement significative, ce que nous attribuons à l'introduction des activités de médiation aux cours de langue de spécialité.

Tableau 5 : Résultats du test-t concernant l'évaluation des étudiants par les enseignants par rapport à la médiation et aux stratégies de médiation (cours de langue de spécialité)

\begin{tabular}{|c|c|c|c|c|c|}
\hline $\begin{array}{l}\text { Évaluation des étudiants par les enseignants- } \\
\text { français }\end{array}$ & & $t$ & Df & $\begin{array}{l}\text { Sig. } \\
(2- \\
\text { tailed) }\end{array}$ & M.D. \\
\hline Médiation & Prétest & 0,801 & 16 & 0,435 & 2,8889 \\
\hline Médiation & $\begin{array}{l}\text { Post- } \\
\text { test }\end{array}$ & 6,332 & 16 & 0,000 & 21,7778 \\
\hline Stratégies Médiation & Prétest & 0,077 & 13,962 & 0,940 & 0,1111 \\
\hline Stratégies Médiation & $\begin{array}{l}\text { Post- } \\
\text { test }\end{array}$ & 5,878 & 13,510 & 0,000 & 6,5556 \\
\hline $\begin{array}{l}\text { Évaluation des étudiants par les enseignants- } \\
\text { italien }\end{array}$ & & $t$ & Df & $\begin{array}{l}\text { Sig. } \\
(2- \\
\text { tailed) }\end{array}$ & M.D. \\
\hline Médiation & Prétest & $-0,261$ & 18 & 0,797 & $-0,3000$ \\
\hline Médiation & $\begin{array}{l}\text { Post- } \\
\text { test }\end{array}$ & 9,208 & 18 & 0,000 & 24,1000 \\
\hline Stratégies Médiation & Prétest & 0,386 & 18 & 0,704 & 0,3000 \\
\hline
\end{tabular}




\begin{tabular}{|l|l|l|l|l|l|}
\hline Stratégies Médiation & $\begin{array}{l}\text { Post- } \\
\text { test }\end{array}$ & 7,783 & 12,458 & $\mathbf{0 , 0 0 0}$ & 8,9000 \\
\hline
\end{tabular}

À son tour, le tableau 6 comporte les résultats de l'autoévaluation des étudiants par rapport à la médiation et aux stratégies de médiation qui a eu lieu lors du cours de langue de spécialité. Il apparait que l'amélioration est statistiquement significative.

Tableau 6 : Résultats du test-t concernant l'autoévaluation des étudiants par rapport à la médiation et aux stratégies de médiation (cours de langue de spécialité)

\begin{tabular}{|c|c|c|c|c|c|}
\hline $\begin{array}{l}\text { Autoévaluation des étudiants en médiation- } \\
\text { français }\end{array}$ & & $\mathbf{t}$ & Df & $\begin{array}{l}\text { Sig. } \\
(2- \\
\text { tailed })\end{array}$ & M.D. \\
\hline Médiation & Prétest & 0,461 & 10,018 & 0,655 & 1,1111 \\
\hline Médiation & $\begin{array}{l}\text { Post- } \\
\text { test }\end{array}$ & 6,257 & 8,999 & 0,000 & 24,3333 \\
\hline Stratégies Médiation & Prétest & 0,077 & 13,962 & 0,940 & 0,1111 \\
\hline Stratégies Médiation & $\begin{array}{l}\text { Post- } \\
\text { test }\end{array}$ & 5,878 & 13,510 & 0,000 & 6,5556 \\
\hline $\begin{array}{l}\text { Autoévaluation des étudiants en médiation- } \\
\text { italien }\end{array}$ & & $\mathbf{t}$ & Df & $\begin{array}{l}\text { Sig. } \\
(2- \\
\text { tailed })\end{array}$ & M.D. \\
\hline Médiation & Prétest & 1,081 & 18 & 0,294 & 1,4000 \\
\hline Médiation & $\begin{array}{l}\text { Post- } \\
\text { test }\end{array}$ & 7,564 & 10,272 & 0,000 & 18,6000 \\
\hline Stratégies Médiation & Prétest & 0,386 & 18 & 0,704 & 0,3000 \\
\hline Stratégies Médiation & $\begin{array}{l}\text { Post- } \\
\text { test }\end{array}$ & 7,783 & 12,458 & 0,000 & 8,9000 \\
\hline
\end{tabular}

Pour ce qui est du cours de traduction spécialisée, les résultats du test-t concernant l'autoévaluation des étudiants en cours de traduction spécialisée et de l'évaluation sommative des traductions des étudiants par les enseignants sont présentés dans le tableau 7. La moyenne des différences des performances est statistiquement significative en fin de semestre, ce qui correspond à l'amélioration de la performance des étudiants grâce à leur participation aux cours de langue avec médiation. 
Tableau 7 : Résultats du test-t concernant l'autoévaluation des étudiants en cours de traduction spécialisée et évaluation/notation des étudiants par les enseignants

\begin{tabular}{|c|c|c|c|c|c|}
\hline Traduction français-grec & & $\mathbf{t}$ & Df & $\begin{array}{l}\text { Sig. } \\
(2- \\
\text { tailed })\end{array}$ & M.D. \\
\hline Autoévaluation de la compréhension de texte (Q7) & Pretest & 0,371 & 16 & 0,715 & 0,1111 \\
\hline Autoévaluation de la compréhension de texte (Q7) & $\begin{array}{l}\text { Post- } \\
\text { test }\end{array}$ & 1,606 & 16 & 0,128 & 0,7778 \\
\hline Extraction de termes (Q3.1) & Pretest & 1,143 & 16 & 0,270 & 1,0000 \\
\hline Extraction de termes (Q3.1) & $\begin{array}{l}\text { Post- } \\
\text { test }\end{array}$ & 2,272 & 16 & 0,037 & 2,2222 \\
\hline $\begin{array}{l}\text { Recours à des textes comparables ou parallèles } \\
\text { (Q6) }\end{array}$ & Pretest & 0,556 & 16 & 0,587 & 0,1111 \\
\hline $\begin{array}{l}\text { Recours à des textes comparables ou parallèles } \\
\text { (Q6) }\end{array}$ & $\begin{array}{l}\text { Post- } \\
\text { test }\end{array}$ & 2,920 & 16 & 0,010 & 1,0000 \\
\hline Compréhension de texte (Q1, Q2, Q4, Q5) & Pretest & $-0,225$ & 16 & 0,825 & $-0,02778$ \\
\hline Compréhension de texte (Q1, Q2, Q4, Q5) & $\begin{array}{l}\text { Post- } \\
\text { test }\end{array}$ & 5,613 & 16 & 0,000 & 0,88889 \\
\hline Notation de la traduction & Pretest & 1,147 & 16 & 0,268 & 0,5556 \\
\hline Notation de la traduction & $\begin{array}{l}\text { Post- } \\
\text { test }\end{array}$ & 3,719 & 16 & 0,002 & 2,4444 \\
\hline Traduction italien-grec & & $\mathbf{t}$ & Df & $\begin{array}{l}\text { Sig. } \\
(2- \\
\text { tailed })\end{array}$ & M.D. \\
\hline Autoévaluation de la compréhension de texte (Q7) & Pretest & 0,878 & 18 & 0,391 & 0,3000 \\
\hline Autoévaluation de la compréhension de texte (Q7) & $\begin{array}{l}\text { Post- } \\
\text { test }\end{array}$ & 2,029 & 18 & 0,057 & 0,9000 \\
\hline Extraction de termes (Q3.1) & Pretest & 0,000 & 18 & 1,000 & 0,0000 \\
\hline Extraction de termes (Q3.1) & $\begin{array}{l}\text { Post- } \\
\text { test }\end{array}$ & 4,241 & 18 & 0,000 & 3,7000 \\
\hline $\begin{array}{l}\text { Recours à des textes comparables ou parallèles } \\
\text { (Q6) }\end{array}$ & Pretest & 1,633 & 18 & 0,120 & 0,4000 \\
\hline $\begin{array}{l}\text { Recours à des textes comparables ou parallèles } \\
\text { (Q6) }\end{array}$ & $\begin{array}{l}\text { Post- } \\
\text { test }\end{array}$ & 2,862 & 18 & 0,010 & 0,9000 \\
\hline
\end{tabular}




\begin{tabular}{|l|l|l|l|l|l|}
\hline Compréhension de texte (Q1, Q2, Q4, Q5) & Pretest & 0,000 & 13,472 & 1,000 & 0,0000 \\
\hline Compréhension de texte (Q1, Q2, Q4, Q5) & $\begin{array}{l}\text { Post- } \\
\text { test }\end{array}$ & 5,935 & 18 & $\mathbf{0 , 0 0 0}$ & 0,87500 \\
\hline Notation de la traduction & Pretest & 1,897 & 18 & 0,074 & 1,0000 \\
\hline Notation de la traduction & $\begin{array}{l}\text { Post- } \\
\text { test }\end{array}$ & 4,978 & 18 & $\mathbf{0 , 0 0 0}$ & 3,1000 \\
\hline
\end{tabular}

\section{Conclusion}

Notre hypothèse de travail, à savoir que les activités de médiation dans un cours de langue de spécialité fonctionnent en complémentarité avec le cours de traduction spécialisée renforçant la compréhension et l'acquisition du lexique spécialisé, a été confirmée. Nous avons voulu montrer que la traduction pédagogique, dans un contexte d'enseignement supérieur (parcours LEA), malgré le petit nombre des participants, semble revêtir un nouveau rôle dans l'enseignement des langues étrangères et, dans ce cas, en cours de langue de spécialité. En effet, la médiation linguistique prônée par les deux versions du CECR et notamment celle de 2016 peut inciter cet enseignement à échapper aux pratiques traditionnelles quelque peu restreintes de version, de thème et d'exercices grammaticaux et de vocabulaire éventuellement utilisées aux cours. En d'autres termes, la médiation linguistique investie dans des formes diversifiées de traduction constitue une approche progressive en didactique des langues. Pour ce qui est de notre expérience didactique, il a été montré que les activités de médiation suivant certains descripteurs du CECR ont contribué à une meilleure acquisition du lexique spécialisé, ce qui a rendu plus efficace la compréhension de textes spécialisés et leur traduction en langue cible en cours de traduction spécialisée. D'ailleurs, cela a été confirmé par les résultats du test-t. Du fait que la deuxième version du CECR constitue une version pilote selon ses auteurs, nous estimons qu'elle élargit les horizons de la médiation linguistique vu le grand nombre de combinaisons de descripteurs, les types de communication (interlinguistique, intralinguistique) et la variation d'activités. De plus, la médiation motive sans doute les étudiants à apprendre une langue étrangère de manière créative du fait qu'elle intègre des éléments culturels nécessaires à une communication interculturelle et plurilingue à laquelle ils peuvent être souvent confrontés dans leur vie professionnelle et sociale.

\section{BIBLIOGRAPHIE}

ADEN Joëlle, 2012, « La médiation linguistique au fondement du sens partagé : vers un paradigme de l'énaction en didactique des langues ", Ela, 2012/3, n¹67, 267-284. 
ARROYO Encarnación, 2008, «L'enseignement de la traduction et la traduction dans l'enseignement », Cahiers de l'APLIUT, Vol. XXVII (1), 80-89.

BESSE Henri, 2004, Méthodes et pratiques des manuels de langue, Paris : Didier Scolaire.

BESSE Henri, 1998, « Trois genres de traduction » in FoRGES Germaine \& BRAUN Alain (eds.), Didactique des langues, traductologie et communication, Bruxelles : DeBoeck, 10-27.

BIEDERMANN Anne, 2014, « La médiation linguistique dans un contexte d'enseignement des langues étrangères ", Synergies Chili, $\mathrm{n}^{\circ} 10,83-91$.

BYRAM Michael, 2008, "Translation and mediation - objectives for language teaching", The Nordic Network for Intercultural Communication (NIC), The Vigdis Finnbogadóttir Institute of Foreign Languages, University of Iceland, http://vigdis.hi.is/ translation_and_mediation_objectives_for_language_teaching

BYRAM Michael, GRIBKOVA Bella \& STARKEY Hugh, 2002, Développer la dimension interculturelle de l'enseignement des langues, Strasbourg : Conseil de l'Europe.

CARRERES Angeles, 2006, "Strange bedfellows: Translation and language teaching. The teaching of translation into L2 in modern language degrees; uses and limitations?", Sixth Symposium on Translation, Terminology and Interpretation in Cuba and Canada, December 2006, Canadian Translators, Terminologists and Interpreters Council Havana, Cuba, http://www.cttic.org/ ACTI/2006/papers/Carreres.pdf CHOVANCOVÁ Barbora, 2016, "Mediation in legal English teaching studies in logic, grammar and rhetoric", Studies in Logic, Grammar and Rhetoric, 45 (1), Bialystok: De Gruyter Open, 21-35, https:// doi.org/10.1515/slgr-2016-0013

CONSEIL DE L'EUROPE, 2001, Cadre européen commun de référence pour les langues : Apprendre, Enseigner, Évaluer, Paris : Didier / Conseil de l'Europe.

CONSEIL DE L'EUROPE, 2009, Relier les examens de langues au Cadre Européen Commun de Référence pour les Langues : Apprendre, enseigner, évaluer (CECRL). Un manuel. Strasbourg : Division des Politiques Linguistiques, https://www.coe.int/t/dg4/linguistic/Source/ManualRevision-proofreadFINAL_fr.doc соок Guy, 2010, Translation in Language Teaching: An Argument for Reassessment, Oxford : Oxford University Press.

coste Daniel \& CAVAlli Marisa, 2015, Éducation, mobilité, altérité. Les fonctions de médiation de l'école, Strasbourg : Conseil de l'Europe, https://www.coe.int/t/dg4/Linguistic/Source/

LE_texts_Source/LE\%202015/Education-Mobility-Otherness_FR.pdf

DUFF Alan, 1989, Translation, Oxford : Oxford University Press.

FERNANDEZ-GUERRA Ana, 2014, "The usefulness of translation in foreign language learning: students' attitudes", International Journal of English Language \& Translation Studies, 2 (1), 153-170. FIELD Andy, 2009, Discovering Statistics Using SPSS, Londres : Sage.

FRANIĆ Ivana, 2014, « De la métataxe à la médiation linguistique : la structure oubliée?», Linguistica LIV, 411-424.

GAULTIER Marie-Thérèse \& MASSELIN Jacques, 1973, « L'Enseignement des Langues de Spécialité à des Étudiants Étrangers », Langue Française, n¹7, Paris : Larousse, 112-123.

HOUSE Juliane, 2009, Translation, Oxford : Oxford University Press. 
KÁROLY Adrienn, 2014, “Translating EU texts in the English BA programme: exploring teachers' views and practices", WoPaLP, 8, 62-79.

KOCOUREK Rostislav, 1991, La langue française de la technique et de la science, Wiesbaden :

Brandstetter Verlag.

KRAMSCH Claire, 2006, "From communicative competence to symbolic competence", The Modern Language Journal, 90 (2), 249-252.

LADMIRAL Jean-René, 1972, « La traduction dans l'institution pédagogique », Langages, n²8, 8-39.

LAVAULT Élisabeth, 1998, « La traduction comme négociation », in DELISLE Jean \& LEE-JAHNKE

Hannelore (eds.), Enseignement de la traduction et traduction dans l'enseignement, Ottawa : Les Presses de l'Université d'Ottawa, 79-95.

LIAO Posen, 2006, "EFL learners' beliefs about and strategy use of translation in English learning", Regional Language Centre Journal, 37 (2), 191-215.

MANGIANTE Jean-Marc, 2002, «Place et rôle du lexique spécialisé dans les discours de français commercial et économique », Recherche et pratiques pédagogiques en langues de spécialité, 21 (4).

MEDIONI Maria-Alice, MAZET Florence \& SÉBAHI Eddy, 2016, « Traduction, médiation et réflexion sur la langue ", Les langues modernes, $n^{\circ} 2$, Paris : APLV, 11-20, http://ma-medioni.fr/sites/default/ files/article_files/traduction_médiation_et_reflexion_sur_la_langue.pdf MOURLHON-DALLIES Florence, 2008, « Langue de spécialité et logiques professionnelles : enseigner le français en fin de cursus professionnalisant » in BERTRAND Olivier \& SCHAFFNER Isabelle (eds.), Le français de spécialité. Enjeux culturels et linguistiques, Paris : Editions de l'Ecole Polytechnique, 71-81. NISSEN Elke, 2011, « Variations autour de la tâche dans l'enseignement / apprentissage des langues aujourd'hui », Alsic, 14, https://journals.openedition.org/alsic/2344

NORD Christiane, 2005 [1988], Text analysis in translation: Theory, methodology, and didactic application of a model for translation-oriented text analysis, Amsterdam : Rodopi.

NORTH Brian \& PICCARDO Enrica, 2016, «Élaborer des descripteurs pour illustrer les aspects de la médiation pour le CECR », https://rm.coe.int/elaborer-des-descripteurs-illustrant-des-aspectsde-la-mediation-pour-/1680713e2d

PEVERATI Costanza, 2013, “Translation in modern language degree courses: a focus on transferable generic skills”, inTRAlinea, 15, http://www.intralinea.org/archive/article/ translation_in_modern_language_degree_courses

PICCARDO Enrica, 2012, « Médiation et apprentissage des langues : pourquoi est-il temps de réfléchir à cette notion ? », ELA, 3 (167), 285-297.

PUREN Christian, 1988, Histoire des méthodologies de l'enseignement des langues vivantes. Paris : CLE International.

PUREN Christian, 1995, « Pour un nouveau statut de la traduction en didactique des langues », Les Langues Modernes, $\mathrm{n}^{\circ} 1$, Paris : APLV, 7-22, http://www.aplv-languesmodernes.org/spip.php? article 4800

PUREN Christian, 2002, «Perspectives actionnelles et perspectives culturelles en didactique des langues-cultures », Les Langues Modernes, ${ }^{\circ} 3$, Paris : APLV, 55-71, https://www.aplvlanguesmodernes.org/spip.php?article844

PYM Anthony, MALMKJÆR Kirsten \& del MAR GUTIÉRREZ-Colón Plana Maria, 2013, The Role of Translation in the Teaching of Languages in the European Union. Studies on Translation and 
Multilingualism, Luxembourg : Publications Office of the European Union, http:// www.termcoord.eu/wp-content/uploads/2013/08/European_Commission.pdf

RANDACCIO Monica, 2012, “Translation and language teaching: translation as a useful teaching resource", in GORI Federica \& TAYLOR Christopher (eds.), Aspetti della didattica e dell'apprendimento delle lingue straniere: contribute dei collaboratori del Centro Linguistico del l'Università di Trieste, v. 2, Trieste : EUT Edizioni Università di Trieste, 78-91.

SCHÄFFNER Christina, 1998, "Qualification for professional translators: translation in language teaching versus teaching translation”, in MALMKJÆR Kirsten (ed.), Translation and Language Teaching: Language Teaching and Translation, Manchester: St Jerome Publishing, 117-133.

SELESKOVITCH Danica \& LEDERER Marianne, 2001 [1984], Interpréter pour traduire, Paris : Didier Érudition.

SPRINGER Claude, 2014, «Regards didactiques sur les technolectes : des langues de spécialité aux communautés professionnelles ", in MESSAOUDI Leila \& LERAT Pierre (eds.), Les technolectes/langues spécialisées en contexte plurilingue, Rabat : Publications du laboratoire Langage et société CNRST URAC 56, 57-78, https://halshs.archives-ouvertes.fr/halshs-01107501

WEISSMANN Dirk, 2012, « La médiation linguistique à l'université : propositions pour un changement d'approche », Ela, 3 (167), 313-324.

\section{ANNEXES}

\section{Annexe 1}

\section{Questionnaire d'autoévaluation et questionnaire d'évaluation de l'étudiant par l'enseignant}

\begin{tabular}{|c|c|c|c|c|c|c|c|}
\hline & Médiation cognitive & & & & & & \\
\hline & & $\begin{array}{l}\text { Pas } \\
\text { du } \\
\text { tout }\end{array}$ & & & & & beaucoup \\
\hline \multirow[t]{3}{*}{ A } & Construire du sens & 0 & 1 & 2 & 3 & 4 & 5 \\
\hline & $\begin{array}{l}\text { Je peux formuler des questions et des commentaires pour } \\
\text { inciter les gens à développer leur pensée et à justifier ou } \\
\text { clarifier leurs opinions. }\end{array}$ & 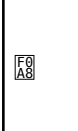 & 㗨 & \begin{tabular}{|ll} 
厚 \\
$A 8$
\end{tabular} & 威 & 監 & 咸 \\
\hline & $\begin{array}{l}\text { Je peux demander aux gens d'expliquer comment une idée } \\
\text { cadre avec le thème principal de la discussion. }\end{array}$ & 屏 & 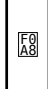 & 喝 & 屏 & 同 & 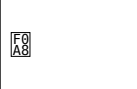 \\
\hline \multirow[t]{2}{*}{ B } & Retransmettre des informations spécifiques à l'oral & & & & & & \\
\hline & Je peux transmettre avec sûreté une information détaillée. & 㗨 & Fo & 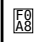 & 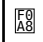 & F⿱ & 原昆 \\
\hline
\end{tabular}




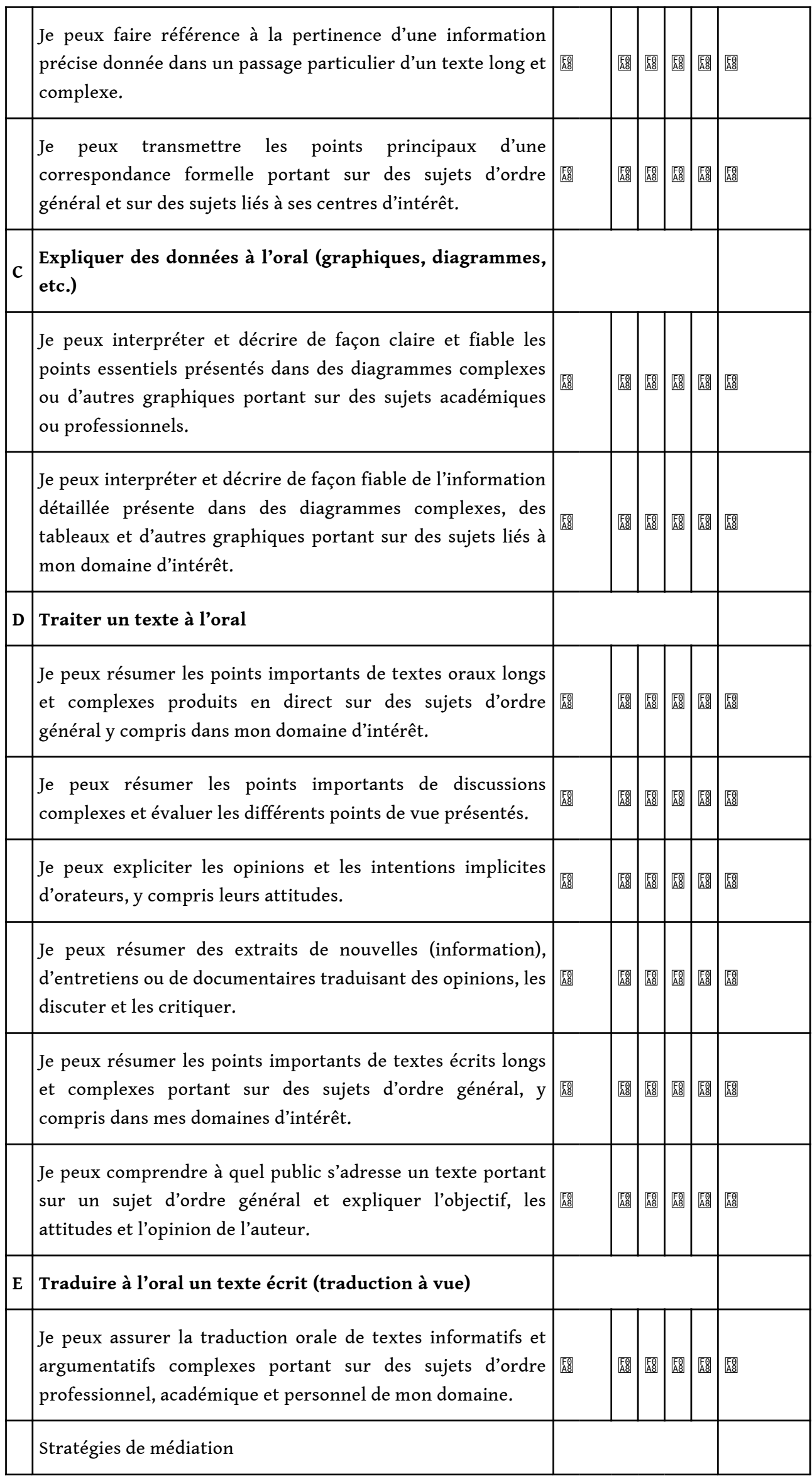




\begin{tabular}{|c|c|c|c|c|c|c|c|c|}
\hline \multirow[t]{2}{*}{$\mathbf{F}$} & Relier à un savoir préalable & & \multirow{2}{*}{\multicolumn{2}{|c|}{ 喝量 }} & \multirow[b]{2}{*}{ 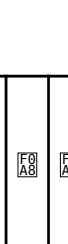 } & & \multirow[b]{2}{*}{ 廆 } & \multirow[b]{2}{*}{ | 袬 } \\
\hline & $\begin{array}{l}\text { Je peux comparer un nouveau savoir ou une information } \\
\text { nouvelle et un savoir ou information déjà connus de façon à } \\
\text { expliquer une notion particulière ou une procédure. }\end{array}$ & 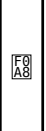 & & & & 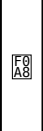 & & \\
\hline \multirow[t]{4}{*}{ G } & Développer un texte & & & & & & & \\
\hline & $\begin{array}{l}\text { Je peux enrichir le contenu d'un texte en ajoutant des } \\
\text { exemples, des raisonnements et des commentaires explicatifs } \\
\text { pour le rendre accessible à un public cible. }\end{array}$ & F䜿 & & 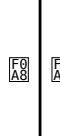 & Fig & 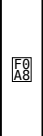 & Fid & 砶 \\
\hline & $\begin{array}{l}\text { Je peux rendre les notions plus accessibles en donnant des } \\
\text { exemples concrets, en récapitulant les étapes une à une et en } \\
\text { répétant les points principaux. }\end{array}$ & F䜿 & & 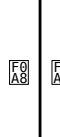 & 辰 & 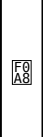 & Fig & 砶 \\
\hline & $\begin{array}{l}\text { Je peux utiliser la répétition et la redondance pour rendre de } \\
\text { nouvelles données plus compréhensibles. }\end{array}$ & F傿 & & 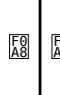 & 屏曷 & 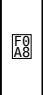 & Fig & F⿱ ${ }_{A B}$ \\
\hline \multirow[t]{3}{*}{$\mathbf{H}$} & Rationaliser un texte & & & & & & & \\
\hline & $\begin{array}{l}\text { Je peux réviser un texte source en supprimant les parties qui } \\
\text { n'ajoutent pas de nouvelles informations importantes pour } \\
\text { un public donné afin de mieux faire comprendre le contenu } \\
\text { essentiel. }\end{array}$ & 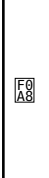 & & 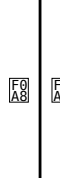 & 凪 & 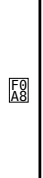 & 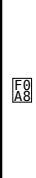 & 原 \\
\hline & $\begin{array}{l}\text { Je peux repérer des informations ayant un rapport entre elles } \\
\text { ou se répétant dans différentes parties d'un texte et les } \\
\text { combiner pour rendre le message essentiel plus clair. }\end{array}$ & 監 & & 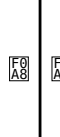 & 屏: & 唒 & Fig & 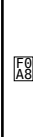 \\
\hline \multirow[t]{2}{*}{ I } & Décomposer une information complexe & & & & & & & \\
\hline & $\begin{array}{l}\text { Je peux faciliter la compréhension d'une question difficile en } \\
\text { présentant séparément les divers éléments de l'argument. }\end{array}$ & 喝 & & 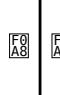 & 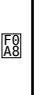 & 间 & Fi: & 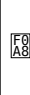 \\
\hline \multirow[t]{2}{*}{$\mathbf{J}$} & Adapter son langage & & & & & & & \\
\hline & $\begin{array}{l}\text { Peut faciliter la compréhension de notions difficiles } \\
\text { rencontrées dans des textes oraux ou écrits complexes en les } \\
\text { paraphrasant. }\end{array}$ & 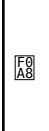 & & 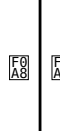 & {$\left[\begin{array}{ll}F \\
A B\end{array}\right]$} & 監 & 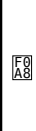 & 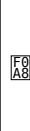 \\
\hline
\end{tabular}




\section{Annexe 2}

\section{Annexe 2.1}

\begin{tabular}{|c|c|c|c|c|}
\hline \multirow{2}{*}{ A. } & \multicolumn{2}{|c|}{ terme français } & traduction en grec & terme italien \\
\hline & \multicolumn{2}{|c|}{ 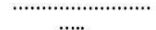 } & $\cos \theta \dot{\alpha}$ & beni \\
\hline \multicolumn{5}{|c|}{ 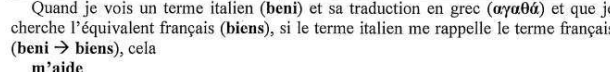 } \\
\hline & $\square$ & $\square$ & $\square$ & $\square$ \\
\hline \multirow{2}{*}{\multicolumn{2}{|c|}{$\begin{array}{l}\text { Pas du tout [0] } \\
\text { ou } \\
\text { m'embrouille }\end{array}$}} & Un peu & Assez & Beaucoup [3] \\
\hline & & \multirow[b]{2}{*}{$\square$} & & \\
\hline \multicolumn{2}{|c|}{$\square$} & & $\square$ & $\square$ \\
\hline \multicolumn{2}{|c|}{ Pas du tout [0] } & Un peu & Assez & Beaucoup [-3] \\
\hline \multirow{2}{*}{ B. } & \multirow{2}{*}{\multicolumn{2}{|c|}{$\begin{array}{l}\text { terme français } \\
\text { Jour férié }\end{array}$}} & traduction en grec & terme italien \\
\hline & & & & Giorno festivo \\
\hline \multicolumn{5}{|c|}{$\begin{array}{l}\text { Quand je vois un terme français (Jour férié) et l'équivalent italien qui lu } \\
\text { ressemble (Jour férié } \rightarrow \text { Giorno festivo) ot que je cherche l'équivalent du term } \\
\text { français en grec (Apy'ía), cela } \\
\text { m’aide }\end{array}$} \\
\hline \multicolumn{2}{|c|}{$\square$} & $\square$ & $\square$ & $\square$ \\
\hline \multicolumn{2}{|c|}{$\begin{array}{l}\text { Pas du tout }[0] \\
\text { ou } \\
\text { m'embrouille }\end{array}$} & Un peu & Assez & Beaucoup [3] \\
\hline \multicolumn{2}{|c|}{$\square$} & $\square$ & $\square$ & $\square$ \\
\hline \multicolumn{2}{|c|}{ Pas du tout [0] } & Un peu & Assez & Beaucoup $[-3]$ \\
\hline \multirow[t]{2}{*}{ C. } & \multicolumn{2}{|c|}{ terme français } & traduction en grec & terme italien \\
\hline & \multicolumn{2}{|c|}{$\ldots$} & $\ldots \ldots \ldots \ldots \ldots \ldots$ & $\begin{array}{cc}\text { Permesso } \\
\text { lavoro }\end{array}$ \\
\hline \multicolumn{5}{|c|}{ 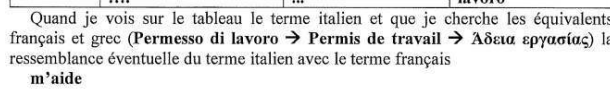 } \\
\hline \multicolumn{2}{|c|}{$\square$} & $\square$ & $\square$ & $\square$ \\
\hline \multicolumn{2}{|c|}{$\begin{array}{l}\text { Pas du tout [0] } \\
\text { ou } \\
\text { m'embrouille }\end{array}$} & Un peu & Assez & Beaucoup [3] \\
\hline \multicolumn{2}{|c|}{$\square$} & $\square$ & $\square$ & $\square$ \\
\hline \multicolumn{2}{|c|}{ Pas du tout [0] } & Un peu & Assez & Beaucoup [-3] \\
\hline
\end{tabular}




\section{Annexe 2.2}

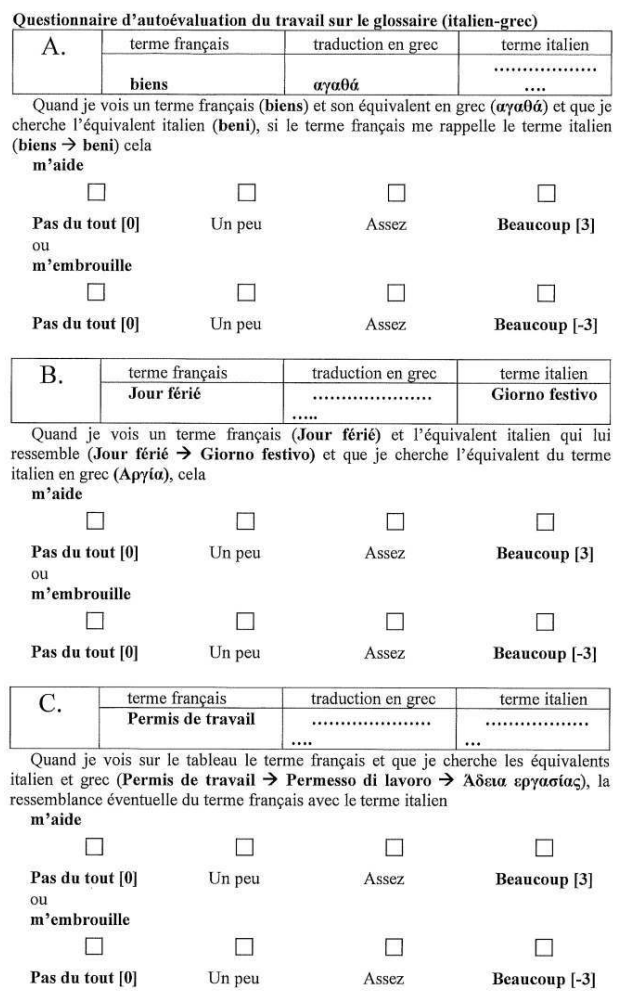

\section{Annexe 3}

\begin{tabular}{|c|c|c|c|c|c|}
\hline \multicolumn{6}{|c|}{$\begin{array}{l}\text { 1. Quand vous lisiez le texte en langue étrangère, quel était votre degré de } \\
\text { compréhension? }\end{array}$} \\
\hline$\square$ & $\square$ & $\square$ & $\square$ & $\square$ & $\square$ \\
\hline Pas du tout $[0]$ & 1 & 2 & 3 & 4 & beaucoup [5] \\
\hline \multicolumn{6}{|c|}{$\begin{array}{l}\text { 2. A-t-il été facile pour vous de repérer et de rendre en grec les termes du } \\
\text { texte? }\end{array}$} \\
\hline$\square$ & $\square$ & $\square$ & $\square$ & $\square$ & $\square$ \\
\hline Pas du tout $[0]$ & 1 & 2 & 3 & 4 & beaucoup [5] \\
\hline \multicolumn{6}{|c|}{ 3.1 Combien de termes avez-vous repérés au total? } \\
\hline \multicolumn{6}{|c|}{3.2 Combien y avait-il de termes connus? } \\
\hline \multicolumn{6}{|c|}{ 3.3 Combien y avait-il de termes inconnus ? } \\
\hline \multicolumn{6}{|c|}{$\begin{array}{l}\text { 4. Lorsque vous ne comprene } \\
\text { l'idée générale du contenu? }\end{array}$} \\
\hline$\square$ & $\square$ & $\square$ & $\square$ & $\square$ & $\square$ \\
\hline Pas du tout $[0]$ & 1 & 2 & 3 & 4 & beaucoup [5] \\
\hline \multicolumn{6}{|c|}{$\begin{array}{l}\text { 5. Vous arrive-t-il souvent de trouver les moyens de traduire le texte même si } \\
\text { vous ne connaissez pas tous les mots dont vous avez besoin? }\end{array}$} \\
\hline$\square$ & $\square$ & $\square$ & $\square$ & $\square$ & $\square$ \\
\hline Pas du tout [0] & 1 & 2 & 3 & 4 & beaucoup [5] \\
\hline \multicolumn{6}{|c|}{$\begin{array}{l}\text { 6. Avez-vous souvent recours à des textes parallèles ou comparables lorsque } \\
\text { vous traduisez? }\end{array}$} \\
\hline$\square$ & $\square$ & $\square$ & $\square$ & $\square$ & $\square$ \\
\hline Pas du tout $[0]$ & 1 & 2 & 3 & 4 & beaucoup [5] \\
\hline \multicolumn{6}{|c|}{$\begin{array}{l}\text { 7. D'après vos réponses ci-dessus, évaluez votre compréhension globale en } \\
\text { langue de spécialité. }\end{array}$} \\
\hline$\square$ & $\square$ & $\square$ & $\square$ & $\square$ & $\square$ \\
\hline Pas du tout [0] & 1 & 2 & 3 & 4 & beaucoup [5] \\
\hline
\end{tabular}




\section{RÉSUMÉS}

L'objectif de cet article est de présenter une démarche exploratoire ayant eu lieu dans un Département LEA et prenant appui sur les descripteurs du CECR récemment développés pour la médiation linguistique. Cette démarche vise la dynamique de la combinaison des activités et des stratégies de médiation en cours de langue de spécialité avec des activités de traduction spécialisée en vue d'une amélioration de l'acquisition du lexique spécialisé. Nous nous intéresserons d'abord au statut de la traduction pédagogique en cours de langue de spécialité afin de montrer que l'introduction de la médiation linguistique en tant qu'aspect de la traduction pédagogique constitue une approche progressive et différenciée des activités de traduction et revisite le rôle de la traduction en didactique des langues. Nous procéderons ensuite à une proposition didactique en émettant l'hypothèse que les activités de médiation dans un cours de langue de spécialité fonctionnent en complémentarité avec le cours de traduction spécialisée, renforçant la compréhension et l'acquisition du lexique spécialisé.

The purpose of this article is to present an exploratory approach which took place in an Applied Foreign Languages Department, based on the recently developed CEFR descriptors for crosslinguistic mediation. This approach focuses on the dynamics of the combination of activities and mediation strategies in a specialized language class with activities of specialized translation in order to improve the acquisition of the specialized vocabulary. We will first focus on the status of pedagogical translation in the specialized language class in order to show that the introduction of linguistic mediation as an aspect of pedagogical translation is a progressive and differentiated approach to translation activities and revisits the role of translation into language teaching. We will then proceed to a didactic proposal by hypothesizing that the mediation activities in a specialized language course work in complementarity with the specialized translation course reinforcing the understanding and acquisition of specialized vocabulary.

\section{INDEX}

Mots-clés : médiation linguistique, traduction pédagogique, descripteurs pour la médiation, langue de spécialité, traduction spécialisée, lexique spécialisé

Keywords : linguistic mediation, pedagogical translation, descriptors for mediation, specialized language, specialized translation, specialized vocabulary

\section{AUTEURS}

\section{ELEFTHERIA DOGORITI}

Laboratoire de communication et de comportement organisationnels du Département de Gestion (parcours LEA) de l'Institut Universitaire de Technologie d'Epire - Grèce edogor@teiep.gr

\section{GEORGES ISERIS}

Laboratoire de communication et de comportement organisationnels du Département de Gestion (parcours LEA) de l'Institut Universitaire de Technologie d'Epire - Grèce iserisgn@teiep.gr 


\section{THEODORE VYZAS}

Laboratoire de communication et de comportement organisationnels du Département de Gestion (parcours LEA) de l'Institut Universitaire de Technologie d'Epire - Grèce vyzas@teiep.gr 